January 2018

\title{
EDUCATION AND POVERTY AS FACTORS IN WHITE AND BLACK RURAL AND URBAN PRISON ADMISSION RATES
}

\author{
Pamela Oliver \\ University of Wisconsin - Madison \\ orcid.org/0000-0001-7643-1008
}

\begin{abstract}
The rise in White imprisonment in rural areas has gone almost completely unnoticed and undiscussed until very recently. Using data newly analyzed from the National Corrections Reporting Program restricted files for 2000-2013, this report documents the higher rates of prison admissions for Whites in rural areas and shows that these higher rates are tied to the higher rates of White poverty and lower White educational levels in rural areas. Further, places with less educated White people showed more growth in White imprisonment. Poverty and education explain the urban-rural difference in a statistical sense, but this does not mean that there is no rural-urban difference. Rather, the analysis points to the high concentration of White disadvantage in rural areas and smaller cities. The Black patterns are different: although rates of poverty and high school dropouts are higher in rural areas for Blacks, the correlations are weaker than for Whites and rural areas have lower Black imprisonment rates both before and after controls for education and poverty. Looking at changes in imprisonment rates between 2000-6 and 2007-11, both Black and White imprisonment rose in areas with higher high school dropout rates and lower Black percentages, but the effects of poverty and college graduation rates and percent Hispanic varied by race in multivariate models. Overall, the findings point to the importance both of disaggregating Black and White imprisonment rates and of recognizing that overall national trends obscure marked differences in the trends between places. They also point to concentrated White disadvantage in White rural areas as linked to rising White imprisonment rates. Further research is necessary to understand these trends.
\end{abstract}

There is a story to be told about White incarceration in the United States, as well as the story about the mass incarceration of Black people. Nationally, the Black rate of imprisonment leveled off after the late 1990s, while the White rate continued to climb (figure 1). Underneath this national pattern is the fact that there are different trends in different kinds of places. Because the racial disparity in incarceration is so high, the single largest factor explaining the total incarceration rate in the US is the proportion of the population who are Black. But if you dig into the race-specific incarceration rates, you get a different picture about White incarceration.

In analyzing older data on patterns of prison admission 1988-2001 (Oliver 2017 [2012]) with a goal of understanding why White prison admissions kept going up while Black prison admissions leveled off after 1995, I learned how national trends obscured the different trends happening in different kinds of places. In the prior work, I discovered a trend that had not been noticed in the literature: that White incarceration rates were rising steeply in overwhelminglyWhite non-metropolitan areas and in smaller White-dominated cities, even as they were falling in 
the large metropolitan areas with large Black populations. Black imprisonment rates were also rising in the same places White imprisonment rates were rising, but there are very few Black people in these places, so this had very little impact on the national Black rates. However, a substantial fraction of White people do live in these White-dominated places and these places were the source of the upward White incarceration trend in this period in the 1990s.

There is essentially no academic literature on this trend. When I reviewed the literature for the 2012 working paper, I found literally nothing written about trends in White incarceration nor about trends in rural incarceration. Journalists and a few academics have recently noticed this trend. A 2016 New York Times article called attention to the rise in rural incarceration (Keller and Pearce 2016). A 2017 article by Eli Hager for the Marshall Project (Hager 2017) reports on the trend that Black incarceration declined while White incarceration increased and suggests that differences in the pace of criminal justice reform in cities where Blacks live versus rural areas may be a factor, referencing the New York Times story citing the rise of rural imprisonment. Eason, Zucker and Wildeman (2017) use data on the home addresses of Arkansas prisoners 1993-2003 to compare racial disparities in imprisonment in rural and urban areas, finding that disparities vary more within community types than between community types, and that nonmetropolitan imprisonment rates are higher than would be expected from risk factors like poverty, but they do not examine trends and work only with older data in one state.

My classification of places in my older analysis was crude and I have been working to generate improved data to pin down exactly what was happening both in the 1990s and since 2000. In this working paper, I show the trends I spotted for the 1990s and use roughly comparable classifications to show the same trends in more recent data. Then I use finer geographic breakouts to determine the factors that affect the Black and White prison admission rates in counties and county groups 2000-2014. I find that average poverty and education levels statistically explain the rural-urban difference in White imprisonment and that metropolitan county groups have higher imprisonment rates for both races when poverty and education are controlled. This does not mean that there is no "news" about rural areas, but rather that the news about them is that they are the sites of both high White poverty rates and high White incarceration rates. This study also shows that the decline in Black incarceration has been steepest in urban areas but occurred in all area types after 2007.

Imprisonment rates are not a direct function of crime rates but of political decisions about how to deal with crime and social inequality. Explaining variations across time and place and between groups in imprisonment rates involves investigating multiple factors. But the first step in any explanation is to document the parameters of the thing to be explained. The agenda of this paper is primarily descriptive, to show how imprisonment rates vary and to investigate some basic correlates of these rates.

\section{Methods}

The data source for incarceration is the restricted files of the National Corrections Reporting Program, which includes "county of sentencing” as a variable. For the 1988-2001 analysis, my research team was focused on Black incarceration and urban areas, so we grouped counties into metropolitan areas. All counties in each state that were not in a metropolitan area 
were grouped together, so there are only 27 "non-metropolitan" areas in that older analysis, an insufficient level of disaggregation to determine the factors affecting rural imprisonment rates.

My analysis for 2000-2013 uses counties or county groups. Smaller counties are grouped to line up with the Census Bureau's Public Use Micro Areas (PUMA) to facilitate merger with socio-economic factors. Larger counties are generally treated separately if they as large as or larger than a PUMA. In a few cases, small counties are grouped with adjacent large counties. Some large cities are divided into multiple counties. In particular, each New York City borough is a county. The Census Bureau classifies each county as part of a metropolitan area or not. Some county groups combine metro and non-metro counties. Preliminary analysis indicates that these mixed county groups generally show intermediate patterns between the wholly-metro and wholly-nonmetro county groups. In this analysis, these mixed county groups are treated as nonmetro except for the six "mixed" county groups that have a population greater than 500,000. The next largest "mixed" case has a population of 300,000, while the requirement of meshing with PUMAs means that the minimum county group size is 100,000.

The NCRP (National Corrections Reporting Program) is a voluntary program and not all states participate in every year. The analysis of each period (1988-2001 and 2000-2013) is based on states that reported throughout the period, so that the time trends are not affected by a shifting mix of which states are in the data. An appendix lists the states included in each period. The two series have a different mix of states in them that had complete data so the end of the first series is not exactly comparable to the beginning of the second series, even though the dates overlap. The proportion Black used for classifying places is the average across the period.

The total prison admission rate for each racial group is calculated by dividing the total prison admissions by the population (all ages) for that racial group in that area. The graphs show the rate per 100,000 population. The regression tables use the square root of the prison admission rate as the dependent variable. This is because this transformation makes the distribution of the dependent variable bell-shaped and approximately normal, which is important for correctly calculating significance tests.

Poverty and education rates are calculated from data available from IPUMS ${ }^{1}$ using the population ages 26-65. This has the effect of focusing the income and education measures on working-age adults who have generally completed their education. IPUMS data are available from the 5\% sample of the decennial Census for 2000 and form the American Community Survey for 2007-2011. Other values are interpolated or extrapolated from these data. Analysis in this report uses the averages for 2000-2006 (i.e. the 2000 Census) and 2007-2013 (i.e. the average of the five samples 2007-2011).

In the graphs I use a signed $\mathrm{R}^{2}$ as a measure of the strength of association. This is computed by calculating the correlation coefficient, taking its square, and multiplying by the sign of the correlation coefficient. A positive $\mathrm{R}^{2}$ says that county groups with higher values of one

${ }^{1}$ Integrated Public Use Microdata Series (IPUMS) is a project of the Minnesota Population Center that provides individual-level Census data to researchers in a form that has been anonymized to protect the confidentiality of individuals. Records identify people by PUMA but not lower geographic levels to prevent the possibility of identifying individual people in the records. 
variable tend to have higher values of the other variable; a negative $\mathrm{R}^{2}$ means that county groups that are higher on one variable tend to have lower values on the other variable. The $\mathrm{R}^{2}$ can meaningfully be interpreted as a percent of variance explained, so for example an $\mathrm{R}^{2}$ of .3 can be interpreted as saying that $30 \%$ of the variation in one variable can be accounted for by its correlation with the other variable. Putting the sign back on the $\mathrm{R}^{2}$ makes it possible to also keep track of the sign of the relation.

\section{Descriptive Results I: Trends by Urban versus Rural area}

My “discovery” of rising White prison admissions in rural areas in the 1990s was motivated by trying to understand how it was that Black prison admissions leveled off in the mid-1990s while White imprisonment continued to rise. As I documented in my working paper (Oliver 2017 [2012]), I learned that the apparent leveling off of Black imprisonment after the early 1990s in national trends was a product of steep declines in Black imprisonment in several major metropolitan areas (especially in New York and Florida) coupled with continued rises in other areas with small Black population percentages, as figure 2 shows. Figure 3 shows that the average White imprisonment rate in these same large metro areas was not especially high and showed weaker trends, that White imprisonment was higher in areas with higher Black population percentages and that White imprisonment was growing most steeply in areas with lower Black population percentages. Figure 4 shows how failing to disaggregate by race misses the divergence in trends in Black and White imprisonment rates in areas with large Black populations or high Black population percentages.

Figures 5, 6 and 7 replicate the older analysis as much as possible for 2000-2013. Figure 5 shows that the average Black prison admission rate is much lower where Blacks are a larger percentage of the population. Figure 5 also shows a decline after 2007 in Black imprisonment rates in all area types except nonmetropolitan areas with high Black population percentages, where the rate was not especially high. The decline in the large metro areas is so steep that the Black rate in these areas falls below that for the high percent-Black areas after 2011. There is also a steep decline in the low percent-Black metro areas and a less steep decline in the low percent-Black nonmetro areas.

Figure 6 show that White imprisonment was high and rising in nonmetropolitan areas and falling after 2008 in both the latest metropolitan areas and those with small Black population percentages. Figure 7 shows the trend for all races. As with figure 4, failing to disaggregate by race leads to a focus on high percentage-Black areas and obscures the trend in White imprisonment rates. The decline in imprisonment for both Blacks and Whites in large metro areas and metro areas with small Black population shows up in the combined graphs.

Graphs in the appendix A present these average lines across scatterplots to show how large the average differences are against the full range of variation. It is clear from the scatterplots that these area type differences capture only part of the differences between areas.

\section{Descriptive Results II: Poverty and Education}

This section focuses only on the period 2000-2013. The graphs in this section show scatterplots of the relation between imprisonment rates and poverty or education for county groups 
separately for 2000-2006 and 2007-2013. Circle sizes are proportional to the population for that racial group. Gray circles are urban county groups, red circles are rural, and pink circles are mixed. Lines show Stata's LOWESS (Locally Weighted Scatterplot Smoothing) for each group; this traces the average imprisonment rate (on the vertical axis) for each level of the variable (poverty or education) on the horizontal axis.

Figures 8 (2000-2006) and 9 (2007-2013) show the bivariate White prison admission rate by White percent poor scatterplot and average trends for urban, rural and mixed county groups. There are two important things to see in these graphs. First, rural areas are much more likely to have high poverty rates than urban areas. The areas where less than $5 \%$ of Whites are poor are nearly all urban (gray), while the areas where more than $10 \%$ of Whites are poor are nearly all rural (red). But there are substantial numbers of both rural and urban areas in the $8-12 \%$ White poverty range. Second, the imprisonment rate has a strong positive correlation with the poverty rate in both urban and rural areas, a correlation that is higher in the second period (2007-14) than the first (2000-2006). Most of the areas with very high White incarceration are rural. Third, in the region of overlapping poverty rates, the urban average (the gray line) is above the rural average (the red line). When poverty is statistically controlled, metropolitan areas have higher imprisonment rates than rural areas.

Figures 10 (2000-2006) and 11 (2007-2013) show the same relationships for Black imprisonment and poverty. There are again three things to see in the graphs. First, the correlation between rurality and poverty is much lower than for Whites: there are rural and urban county groups across the full range of Black percent poor. Second, the imprisonment rate is higher on average in metropolitan than rural areas across most of the poverty percentage range, although the rate is higher in rural areas at the low end of the percent poverty range. Third, the correlation between poverty rates and imprisonment is much lower for Black rates than for White rates. In fact, the relation appears to be positive only for urban areas. The correlation for rural areas is actually negative and the line appears relatively flat.

Graphs in the appendix show very similar patterns for both races for measures of education, the percentage that do not have high school degrees, and percent with college degrees. High imprisonment rates are more highly associated with low education for Whites than for Blacks and the difference between urban and rural areas in average educational levels is much larger for Whites than Blacks.

When poverty or educational levels are comparable, metropolitan county groups have higher imprisonment rates than rural county groups for both Whites and Blacks. But there are many urban areas that have very low White poverty rates and many rural areas that have very high White poverty rates. There is a much larger difference between the social conditions in rural and urban areas for Whites than for Blacks. This is related to imprisonment rates.

Descriptive Results III: Racial Mix of Populations

Instead of poverty or education, the stronger predictor of the Black imprisonment rate is the percent Black in an area, with a stronger relation for rural than urban areas. Figures 12 (20002006) and 13 (2007-2013) show that the average Black imprisonment rate is lower in areas with 
high Black population percentages and that this relation is stronger in rural areas and stronger in the later period. The scatter plots also show that the minimum imprisonment rate is fairly consistent across the full range of percent Black but the maximum goes up as the Black population percentage goes down. This is not just a function of greater sampling variability among smaller populations as some of the places with high Black imprisonment rates are quite large. ${ }^{2}$ Figures 14 (2000-2006) and 15 (2007-2013) show that the percent White is not a strong correlate of the White imprisonment rate.

\section{Multivariate Results I: Predicting imprisonment rates.}

Regression is a statistical technique for assessing the effects of several independent variables at once on a dependent variable, prison admission rates in this case. The square of the multiple regression coefficient, $\mathrm{R}^{2}$, is a measure of the extent to which all the independent variables taken together are statistical predictors of the dependent variable. $\mathrm{R}^{2}$ can be interpreted in percentage terms, so an $\mathrm{R}^{2}$ of . 2 can be understood as meaning that $20 \%$ of the variation in the dependent variable has been statistically explained by the independent variables taken together. Another measure of fit is the BIC (Bayesian Information Criterion), which considers how well the independent variables predict the dependent variable when taking account of how many independent variables there are. The BIC number has no natural interpretation, but a smaller BIC means that a model is a better fit.

The dependent variable for the static regressions is the average White or Black rate for the years 2000-2013 combined. A square root transformation makes the distribution of this variable bellshaped and roughly normal, which is important for the validity of the regression but means that the coefficients cannot be easily interpreted. The baseline model controls for the square root of the state imprisonment rate, and says that there is substantial variation between states in imprisonment rates. Other factors in subsequent models are capturing variation from the state average. To the extent that states have different mixes of rural and urban areas that affect their overall state rates, this is captured in the state average.

Table 1 is the regression for the White imprisonment rate. Consistent with the scatterplots, the coefficient on metropolitan is negative in model 1: urban county groups have lower average imprisonment rates than rural county groups. Model 2 shows that this relation stays negative when the Black and Hispanic population percentages are included, but becomes positive in model 3 when controls are introduced for poverty and education, as we saw in the scatterplots. The changes in $\mathrm{R}^{2}$ from the baseline model indicate that poverty and education make the largest contributions to explaining White imprisonment rates: the $\mathrm{R}^{2}$ for model 3 is .671 or .127 higher than for the baseline $\mathrm{R}^{2}$ of .544 . By contrast, percent Black and percent Hispanic have an $\mathrm{R}^{2}$ change of only .026, and adding these variables in model 4 adds only .009 to the $\mathrm{R}^{2}$. That is, model 3 is the best predictor and poverty and education are the strong factors predicting variations in White imprisonment rates in county groups off the state average. Model 3 also has the smallest BIC.

\footnotetext{
2 The grey circle (large urban area) with a high percent Black (65\%) and an unusually high Black prison admission rate is Baltimore County, Maryland.
} 
These results say that, net of controls for poverty and education, White prison admission rates are higher in urban areas. Racial composition, especially the percent Hispanic, is also associated with White prison admission rate: White prison admissions are higher in areas with more Hispanics, although the pattern of effects as other variables are added suggests issues of collinearity among high school dropout rates and percent Hispanic. Collinearity means that the same places have both high White dropout rates and high Hispanic percentages. Further analysis will be needed to sort out how Hispanic population proportions are related to White imprisonment. The areas with large Hispanic populations are in Florida and the Southwest (especially California, Texas, Arizona, New Mexico).

Table 2 shows the same set of models for the Black rates. Poverty and education again are the strongest predictor set with an $\mathrm{R}^{2}$ change of .11 over the baseline model. However, percent Black adds an additional .068 to the $\mathrm{R}^{2}$ in model 4. For the Black imprisonment rate again the strongest predictors are the percent poor among Blacks and the percent college graduates. Black imprisonment rates are consistently higher in urban than rural areas and the strength of this effect becomes stronger with controls for racial composition and poverty and education levels. The percent Black coefficient is negative, as we would expect from the scatterplots.

\section{Multivariate Results II: Predicting Changes in Imprisonment Rates}

In tables 3 and 4, the dependent variable is the change in the square root of the rate between the 2000-2006 average and the 2007-2013 average. The baseline model controls for both the average change in the state and the lagged (2000-2006) level of the rate. Each table shows the change in $\mathrm{R}^{2}$ from the baseline model for each set of independent variables as well as BIC tests which indicate which model is the best fit, balancing explained variance with the number of predictors. Figures 17-20 and the figures in Appendix C show the bivariate scatterplots that undergird these regressions.

Table 3 for the White rate shows that, as with the static models, the change in White imprisonment is higher in non-metropolitan counties, but the coefficient becomes positive (although not significant) when poverty and education are controlled. The best-fitting model is (4). The percent Black and Hispanic add .014 to the $\mathrm{R}^{2}(.034-.02)$ while poverty and education add .069 to the $\mathrm{R}^{2}(.089-.02)$. When all the variables are included in model 4 , both the percent Hispanic and the percent poor become nonsignificant, suggesting that educational levels and the percent Black are the strongest predictors. Model 5, which adds the change in poverty and education to the model adds only .002 to the $\mathrm{R}^{2}$; model 5 also has a higher BIC. White imprisonment grew more where Whites were less educated and poorer and where Blacks were a smaller percentage of the population. The tight correlation between low education and rurality can be seen in figure 17 along with the bivariate effect on the change in the imprisonment rate. Although there is no difference between rural and urban areas in the average rate of change in the period of the graph where they overlap, all the places with very high White high school dropout rates are rural and they all have relatively high changes in imprisonment rates. At the other end of the distribution, nearly all the places with very low White high school dropout rates are urban, and many of them saw declines in the White imprisonment rate. Figure 18 shows that rural places are disproportionately those with very small minority populations and high percent 
White, and that in both urban and rural county groups White imprisonment rose more where Whites were an overwhelming majority of the population than in places (mostly urban) where there was a higher percentage of non-Whites.

Table 4 shows the regression for the Black imprisonment rate. As with the static models, the explanatory power of poverty and education is lower and the explanatory power of racial demographics is higher for the Black rate than the White rate. The BIC is again lowest for model 4. The percent Black and Hispanic add .042 to the $\mathrm{R}^{2}(.051-.009)$ in model 2 while poverty and education add .015 to the $\mathrm{R}^{2}(.024-.009)$ in model 3 . The coefficients in model 4 suggest that both the percent Black and the percent Hispanic are associated with declines in the Black imprisonment rate while both the percent poor and the percent high school dropouts are associated with rises in the Black rate (or smaller declines). Figure 19 shows the scatterplot for the relation between percentage high school drop outs and the change in the prison admission rate; the relationship is positive, but weaker than for the White rate. Figure 20, the bivariate scatterplot of the Black population percentage the change, shows a zero relationship, indicating that the negative effect in the regression shows up only with controls. The scatterplot indicates little difference between urban and rural places in the average change in Black imprisonment rates and, unlike the White graph, a much lower correlation between education and rurality.

To sum up, White imprisonment rates generally rose between 2000 and 20013. The highest rate of growth in White imprisonment between 2000-2006 and 2007-2013 was in rural areas where Whites had high dropout rates and high poverty rates and were a very high percentage of the population. White imprisonment rates fell in the large urban areas with high minority populations, higher White educational levels, and lower White poverty. By contrast, Black imprisonment rates generally declined and the decline generally occurred in urban areas with higher Black and Hispanic population percentages and lower rates of Black poverty and Black high school dropouts.

\section{Discussion}

White imprisonment rates went up while Black imprisonment rates went down in the 2000s and early 2010s. Unpacking the patterns, we found that different things happened in different places. The rise in White rates occurred in all area types except the largest metro areas through 2008 but after 2008 was concentrated in rural areas, while White rates fell in large metro areas and those with smaller minority populations. Black prison admission rates were generally declining, with the steepest drops in metro areas.

The association between high and rising White imprisonment rates and rural areas is statistically explained by the fact that Whites in many rural areas have high poverty rates and low educational levels, and that the very highest White poverty rates and lowest educational levels are found almost exclusively in rural areas, while the very lowest White poverty rates and highest educational levels are found almost exclusively in urban areas. Comparing places with comparable White poverty and educational levels, the average White imprisonment rates are higher in urban than rural areas. This does not mean that there is no "story" about whites in rural areas, but it does mean that the story seems to be about how poverty and low education are concentrated for Whites in rural areas. The regression models controlled for the average state 
rate so are showing how places varied within states. But the scatterplots also show that there is wide variation between places around these trends, so there is more to understand about what affects imprisonment than just poverty and education.

These associations do not say why this is happening. There is a tendency to assume that imprisonment rates rise and fall with crime rates, but this is not true. A great deal of research tracking the rise of mass incarceration showed that imprisonment went up while crime went down. High rates of imprisonment were due to a punitive drug war, longer sentences per crime, and rising rates of revocation.

Black imprisonment rates fell in many areas as White imprisonment rates were rising. The decline in Black imprisonment was most pronounced in large metropolitan areas that had previously experienced huge increases in Black imprisonment around the racialized drug war. White imprisonment rates also fell in many of these same urban areas, although generally not as steeply as the Black rates fell. Again, there is variation around these trends and a need to explore them more thoroughly.

There has been a great deal of news coverage of the opiate crisis among Whites, and one specific avenue for future study is to explore the trends for drug sentences versus other kinds of sentences, and to examine the trends in drug deaths and arrests for drug offenses. However, the lessons from the experience of mass incarceration of Black Americans around the drug war should remind us that punitive responses are more driven by politics and funding patterns than by rates of drug abuse. A full understanding of the ups and downs of mass incarceration requires a willingness to get beyond simple tropes to look at how incarceration is produced and the many politicized steps that occur between offending and imprisonment.

This working paper does not provide a full explanation for the racial patterns of incarceration. Rather, it points to the importance of asking new questions and doing more analysis that is focused on identifying the factors that affect different racial groups differently in different places. 


\section{References}

Eason, John M., Danielle Zucker and Christopher Wildeman. 2017. "Mass Imprisonment across the Rural-Urban Interface." The Annals of the American Academy of Political and Social Science 672(1):202-16. doi: doi:10.1177/0002716217705357.

Hager, Eli. 2017. "A Mass Incarceration Mystery. Why Are Black Imprisonment Rates Going Down? Four Theories." in The Marshall Project. https://www.themarshallproject.org/2017/12/15/a-mass-incarceration-mystery.

Keller, Josh and Adam Pearce. 2016. "The Upshot: "This Small Indiana County Sends More People to Prison Than San Francisco and Durham, N.C., Combined. Why?"." in The New York Times.

Oliver, Pamela. 2017 [2012]. "Prison Sentence Trends by Area Type 1985-2001." in SocArXiv. osf.io/preprints/socarxiv/3nw8q. 
Table 1. Regression of Average White Imprisonment Rate (sqrt) 2000-2013 on independent Variables

\begin{tabular}{|c|c|c|c|c|c|}
\hline Independent Variable & baseline & (1) & (2) & (3) & (4) \\
\hline \multirow[t]{2}{*}{ Metro county groups } & & $-0.726 * * *$ & $-0.694 * * *$ & $0.773 * * *$ & $0.684 * * *$ \\
\hline & & {$[0.155]$} & {$[0.160]$} & {$[0.195]$} & [0.195] \\
\hline \multirow[t]{2}{*}{$\%$ Black } & & & $-2.911^{* * *}$ & & $-1.426^{*}$ \\
\hline & & & {$[0.797]$} & & [0.743] \\
\hline \multirow[t]{2}{*}{$\%$ Hispanic } & & & 0.639 & & $3.015^{* * *}$ \\
\hline & & & [1.116] & & [1.093] \\
\hline \multirow[t]{2}{*}{$\%$ Poor } & & & & $22.78 * * *$ & $19.13^{* * *}$ \\
\hline & & & & {$[3.802]$} & [4.064] \\
\hline \multirow[t]{2}{*}{$\%$ Not High School Grad } & & & & $-9.555^{* * *}$ & -4.612 \\
\hline & & & & {$[2.942]$} & [2.851] \\
\hline \multirow[t]{2}{*}{$\%$ College Grad } & & & & $-10.50 * * *$ & $-10.05^{* * *}$ \\
\hline & & & & {$[1.259]$} & [1.184] \\
\hline \multirow[t]{2}{*}{ State Average Rate } & $1.000 * * *$ & $0.981 * * *$ & $0.983 * * *$ & $0.878 * * *$ & $0.854 * * *$ \\
\hline & [0.0362] & {$[0.0361]$} & [0.0350] & {$[0.0335]$} & [0.0330] \\
\hline \multirow[t]{2}{*}{ Constant } & 0.237 & $0.848 * *$ & $1.123 * * *$ & $2.836^{* * *}$ & $2.870 * * *$ \\
\hline & [0.383] & [0.404] & {$[0.387]$} & {$[0.553]$} & [0.546] \\
\hline Observations & 726 & 726 & 726 & 726 & 726 \\
\hline R-squared & 0.544 & 0.556 & 0.570 & 0.671 & 0.680 \\
\hline $\mathrm{BIC}$ & 3336 & 3323 & 3313 & 3125 & 3118 \\
\hline R2 change from baseline & & 0.012 & 0.026 & 0.127 & 0.136 \\
\hline
\end{tabular}

Robust standard errors in brackets

*** $\mathrm{p}<0.01,{ }^{* *} \mathrm{p}<0.05,{ }^{*} \mathrm{p}<0.1$ 
Table 2. Regression of Average Black Imprisonment Rate (sqrt) 2000-2013 on independent variables

$\begin{array}{rrrrrr}\text { Independent Variable } & \text { baseline } & (1) & (2) & (3) & (4) \\ \text { Metro county groups } & & & & & \\ & & 1.842^{* * *} & 2.480^{* * *} & 2.968^{* * *} & 3.810^{* * *} \\ \text { \% Black } & & {[0.469]} & {[0.488]} & {[0.562]} & {[0.574]} \\ & & & -10.60^{* * *} & & -16.64^{* * *} \\ \text { \% Hispanic } & & & {[1.583]} & & {[1.632]} \\ & & & -8.537^{* * *} & & -4.047 \\ \text { \% Poor } & & & {[2.961]} & & {[3.016]} \\ & & & & 24.85 * * * & 30.29 * * \\ \text { \% Not High School Grad } & & & & {[3.363]} & {[3.503]} \\ & & & & -0.653 & 2.360 \\ \text { \% College Grad } & & & & -12.05 * * * & -12.73 * * * \\ & & & & {[4.174]} & {[4.076]} \\ \text { State Average Rate } & 0.888^{* * *} & 0.890^{* * *} & 0.830^{* * *} & 0.913 * * * & 0.771^{* * *} \\ & {[0.0514]} & {[0.0504]} & {[0.0588]} & {[0.0460]} & {[0.0531]} \\ \text { Constant } & 4.166^{* * *} & 3.088^{* *} & 6.193 * * * & -0.762 & 3.330^{*} \\ & {[1.258]} & {[1.242]} & {[1.522]} & {[1.945]} & {[1.948]} \\ & & & & & \\ \text { Observations } & 726 & 726 & 726 & 726 & 726 \\ \text { R-squared } & 0.305 & 0.320 & 0.357 & 0.415 & 0.483 \\ \text { BIC } & 4852 & 4843 & 4816 & 4754 & 4677 \\ \text { R2 change from baseline } & & 0.015 & 0.052 & 0.110 & 0.178\end{array}$

Robust standard errors in brackets *** $\mathrm{p}<0.01, * * \mathrm{p}<0.05, * \mathrm{p}<0.1$ 
Table 3. Regression of Change (2000-2006 vs. 2007-2013) in White Imprisonment Rate (sqrt) on independent variables

\begin{tabular}{|c|c|c|c|c|c|c|}
\hline Independent Variable & Baseline & (1) & (2) & (3) & (4) & (5) \\
\hline \multirow[t]{2}{*}{ Metro county groups } & & $-0.465 * * *$ & $-0.368 * * *$ & 0.130 & $0.174^{*}$ & $0.195^{*}$ \\
\hline & & {$[0.0766]$} & {$[0.0796]$} & [0.0962] & {$[0.0971]$} & [0.101] \\
\hline \multirow[t]{2}{*}{$\%$ Black } & & & $-1.269 * * *$ & & $-1.573 * * *$ & $-1.543 * * *$ \\
\hline & & & {$[0.288]$} & & [0.287] & [0.303] \\
\hline \multirow[t]{2}{*}{ \% Hispanic } & & & $-1.411 * * *$ & & -0.748 & -0.609 \\
\hline & & & {$[0.489]$} & & {$[0.466]$} & [0.476] \\
\hline \multirow[t]{2}{*}{ Lag \% poor } & & & & $5.862 * * *$ & $4.014^{*}$ & $3.843^{*}$ \\
\hline & & & & [2.179] & {$[2.077]$} & [2.196] \\
\hline \multirow[t]{2}{*}{ Lag \% not high school grad } & & & & $3.843 * * *$ & $6.855^{* * *}$ & $6.334 * * *$ \\
\hline & & & & {$[1.360]$} & [1.509] & [1.911] \\
\hline \multirow[t]{2}{*}{ Lag \% college grad } & & & & $-2.936 * * *$ & $-2.020 * * *$ & $-1.814 * * *$ \\
\hline & & & & {$[0.494]$} & {$[0.504]$} & [0.522] \\
\hline \multirow[t]{2}{*}{ Change in \% poor } & & & & & & 1.906 \\
\hline & & & & & & [4.363] \\
\hline \multirow[t]{2}{*}{ Change in $\%$ not $\mathrm{HS}$ grad } & & & & & & -3.734 \\
\hline & & & & & & [5.487] \\
\hline \multirow[t]{2}{*}{ Change in $\%$ college grad } & & & & & & -5.597 \\
\hline & & & & & & [3.449] \\
\hline \multirow[t]{2}{*}{ Lag imprisonment rate } & $-0.0383 * *$ & $-0.0515^{* * *}$ & $-0.0491 * * *$ & $-0.129 * * *$ & $-0.129 * * *$ & $-0.131 * * *$ \\
\hline & [0.0154] & {$[0.0151]$} & [0.0149] & [0.0173] & {$[0.0168]$} & {$[0.0170]$} \\
\hline \multirow[t]{2}{*}{ State average change in rate } & $1.019 * * *$ & $0.993 * * *$ & $0.977 * * *$ & $0.823 * * *$ & $0.798 * * *$ & $0.800 * * *$ \\
\hline & {$[0.0441]$} & [0.0427] & {$[0.0448]$} & {$[0.0407]$} & [0.0403] & [0.0407] \\
\hline \multirow[t]{2}{*}{ Constant } & $0.514^{* * *}$ & $0.930 * * *$ & $1.122^{* * *}$ & $1.464^{* * *}$ & $1.327^{* * *}$ & $1.374^{* * *}$ \\
\hline & [0.168] & [0.178] & [0.175] & [0.267] & {$[0.258]$} & {$[0.256]$} \\
\hline Observations & 726 & 726 & 726 & 726 & 726 & 726 \\
\hline R-squared & 0.568 & 0.588 & 0.602 & 0.657 & 0.670 & 0.672 \\
\hline $\mathrm{BIC}$ & 2278 & 2251 & 2240 & 2138 & 2123 & 2139 \\
\hline R2 change from baseline & & 0.020 & 0.034 & 0.089 & 0.102 & 0.104 \\
\hline
\end{tabular}

Robust standard errors in brackets

*** $\mathrm{p}<0.01,{ }^{* *} \mathrm{p}<0.05,{ }^{*} \mathrm{p}<0.1$ 
Table 4. Regression of Change (2000-2006 vs. 2007-2013) in Black Imprisonment Rate (sqrt) on independent variables

\begin{tabular}{|c|c|c|c|c|c|c|}
\hline Independent Variable & Baseline & (1) & (2) & (3) & (4) & (5) \\
\hline Metro counties & & $\begin{array}{c}-0.719 * * * \\
{[0.219]}\end{array}$ & $\begin{array}{l}-0.266 \\
{[0.229]}\end{array}$ & $\begin{array}{c}-0.406 \\
{[0.249]}\end{array}$ & $\begin{array}{c}0.256 \\
{[0.262]}\end{array}$ & $\begin{array}{c}0.200 \\
{[0.260]}\end{array}$ \\
\hline \% Black & & & $\begin{array}{c}-5.445^{* * *} \\
{[0.694]}\end{array}$ & & $\begin{array}{c}-7.482 * * * \\
{[0.834]}\end{array}$ & $\begin{array}{c}-7.544 * * * \\
{[0.842]}\end{array}$ \\
\hline \% Hispanic & & & $\begin{array}{c}-5.882^{* * *} \\
{[1.350]}\end{array}$ & & $\begin{array}{c}-4.687^{* * *} \\
{[1.344]}\end{array}$ & $\begin{array}{c}-4.506 * * * \\
{[1.374]}\end{array}$ \\
\hline Lag \% poor & & & & $\begin{array}{c}1.919 \\
{[1.927]}\end{array}$ & $\begin{array}{c}5.096 * * * \\
{[1.967]}\end{array}$ & $\begin{array}{c}5.800 * * * \\
{[2.117]}\end{array}$ \\
\hline Lag \% not high school grad & & & & $\begin{array}{c}6.133 * * * \\
{[2.336]}\end{array}$ & $\begin{array}{c}6.584^{* * *} \\
{[2.221]}\end{array}$ & $\begin{array}{c}6.265^{* *} \\
{[3.142]}\end{array}$ \\
\hline Lag \% college grad & & & & $\begin{array}{c}0.925 \\
{[2.161]}\end{array}$ & $\begin{array}{c}-0.755 \\
{[2.130]}\end{array}$ & $\begin{array}{c}-0.316 \\
{[2.198]}\end{array}$ \\
\hline Change in \% poor & & & & & & $\begin{array}{c}1.631 \\
{[2.799]}\end{array}$ \\
\hline Change in \% not HS grad & & & & & & $\begin{array}{l}-1.584 \\
{[3.825]}\end{array}$ \\
\hline Change in \% college grad & & & & & & $\begin{array}{c}1.527 \\
{[3.093]}\end{array}$ \\
\hline Lag imprisonment rate & $\begin{array}{c}-0.146 * * * \\
{[0.0193]}\end{array}$ & $\begin{array}{c}-0.140 * * * \\
{[0.0192]}\end{array}$ & $\begin{array}{c}-0.166 * * * \\
{[0.0187]}\end{array}$ & $\begin{array}{c}-0.145^{* * *} \\
{[0.0205]}\end{array}$ & $\begin{array}{c}-0.195^{* * *} \\
{[0.0207]}\end{array}$ & $\begin{array}{c}-0.197^{* * *} \\
{[0.0211]}\end{array}$ \\
\hline State average change in rate & $\begin{array}{c}0.760 * * * \\
{[0.0671]}\end{array}$ & $\begin{array}{c}0.761^{* * *} \\
{[0.0670]}\end{array}$ & $\begin{array}{c}0.708^{* * *} \\
{[0.0670]}\end{array}$ & $\begin{array}{c}0.719 * * * \\
{[0.0677]}\end{array}$ & $\begin{array}{c}0.648 * * * \\
{[0.0662]}\end{array}$ & $\begin{array}{c}0.651^{* * *} \\
{[0.0662]}\end{array}$ \\
\hline Constant & $\begin{array}{c}4.241 * * * \\
{[0.454]}\end{array}$ & $\begin{array}{c}4.472^{* * *} \\
{[0.464]}\end{array}$ & $\begin{array}{c}5.950 * * * \\
{[0.503]}\end{array}$ & $\begin{array}{c}2.841 * * * \\
{[0.911]}\end{array}$ & $\begin{array}{c}4.588^{* * *} \\
{[0.900]}\end{array}$ & $\begin{array}{c}4.452^{* * *} \\
{[1.016]}\end{array}$ \\
\hline Observations & 726 & 726 & 726 & 726 & 726 & 726 \\
\hline R-squared & 0.391 & 0.400 & 0.442 & 0.415 & 0.472 & 0.473 \\
\hline $\mathrm{BIC}$ & 3777 & 3773 & 3734 & 3774 & 3713 & 3731 \\
\hline R2 change from baseline & & .009 & .051 & .024 & .081 & .082 \\
\hline
\end{tabular}

Robust standard errors in brackets

*** $\mathrm{p}<0.01, * * \mathrm{p}<0.05$, * $\mathrm{p}<0.1$ 
Figures for Pamela Oliver "Education and Poverty as Factors in White and Black Rural and Urban Prison Admission Rates

January 2018 
Figure 1

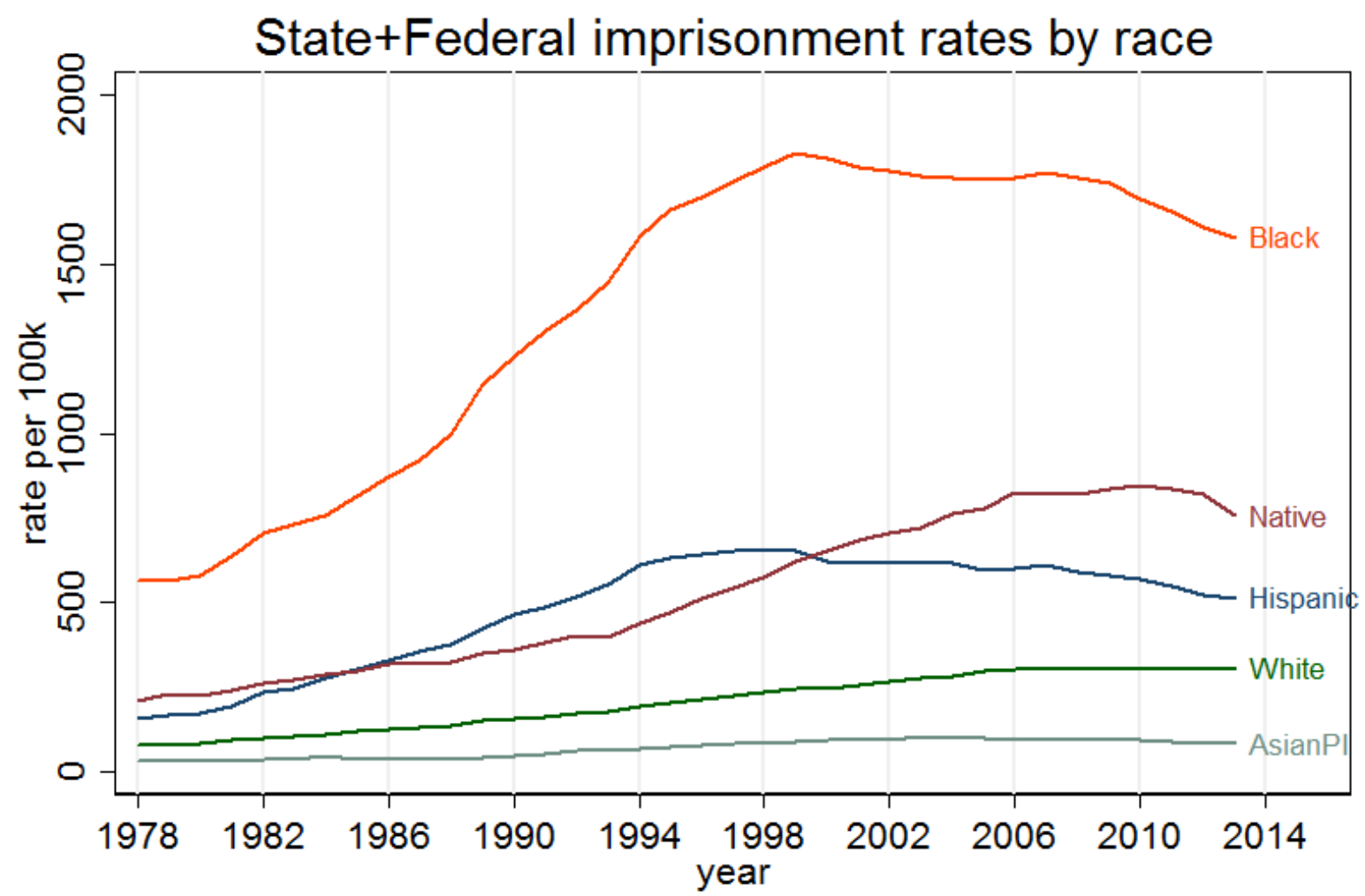

NPS data cleaned by Pamela Oliver Nov. 2016. orcid.org/0000-0001-7643-1008 Rate per 100,000 population all ages of State+Federal imprisonment 
Figure 2

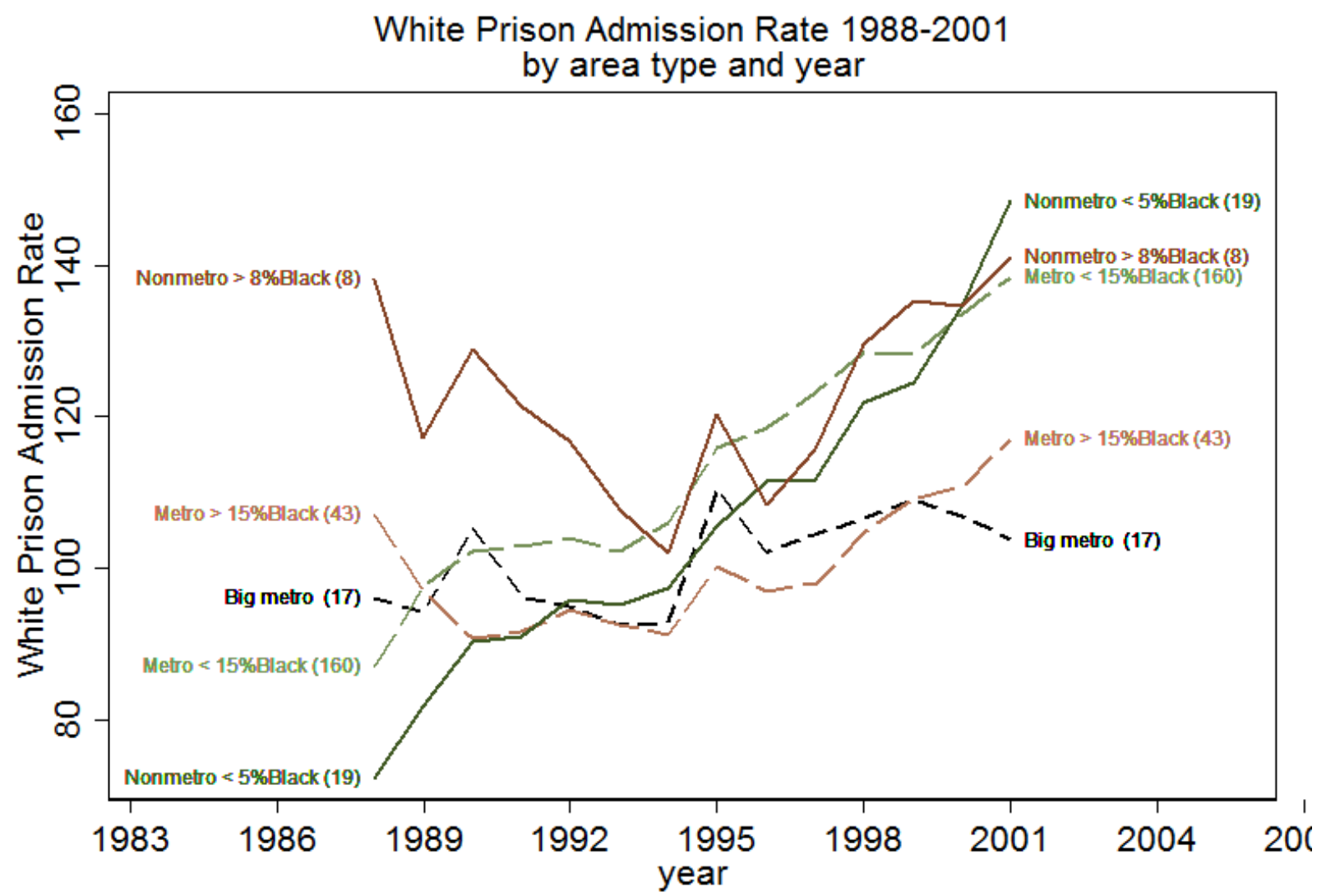

Metro areas and non-metro state balances for 28 states with complete data. N's in labels. 
Figure 3

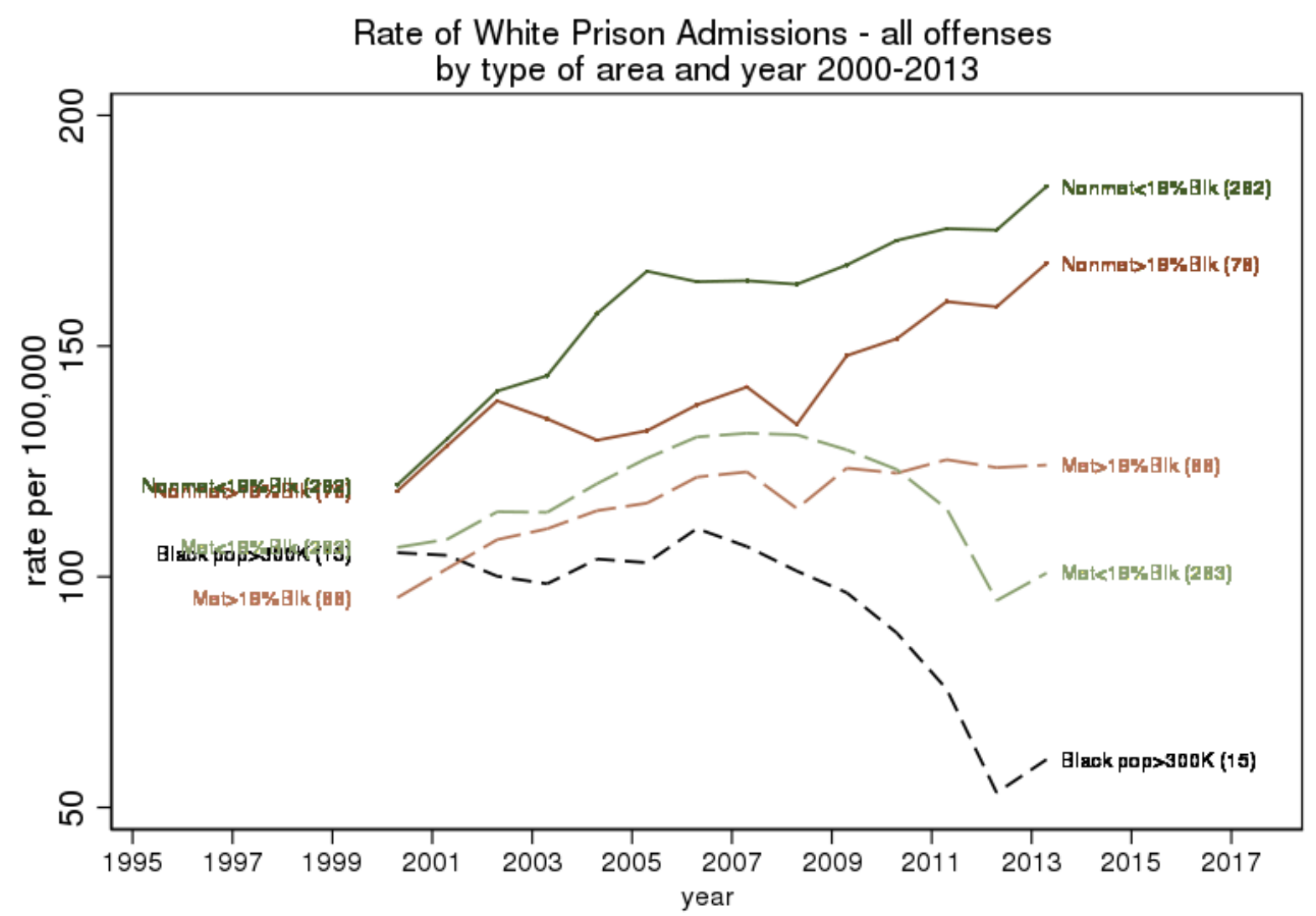

726 county groups in 32 states with complete data 2000-2013 
Figure 4

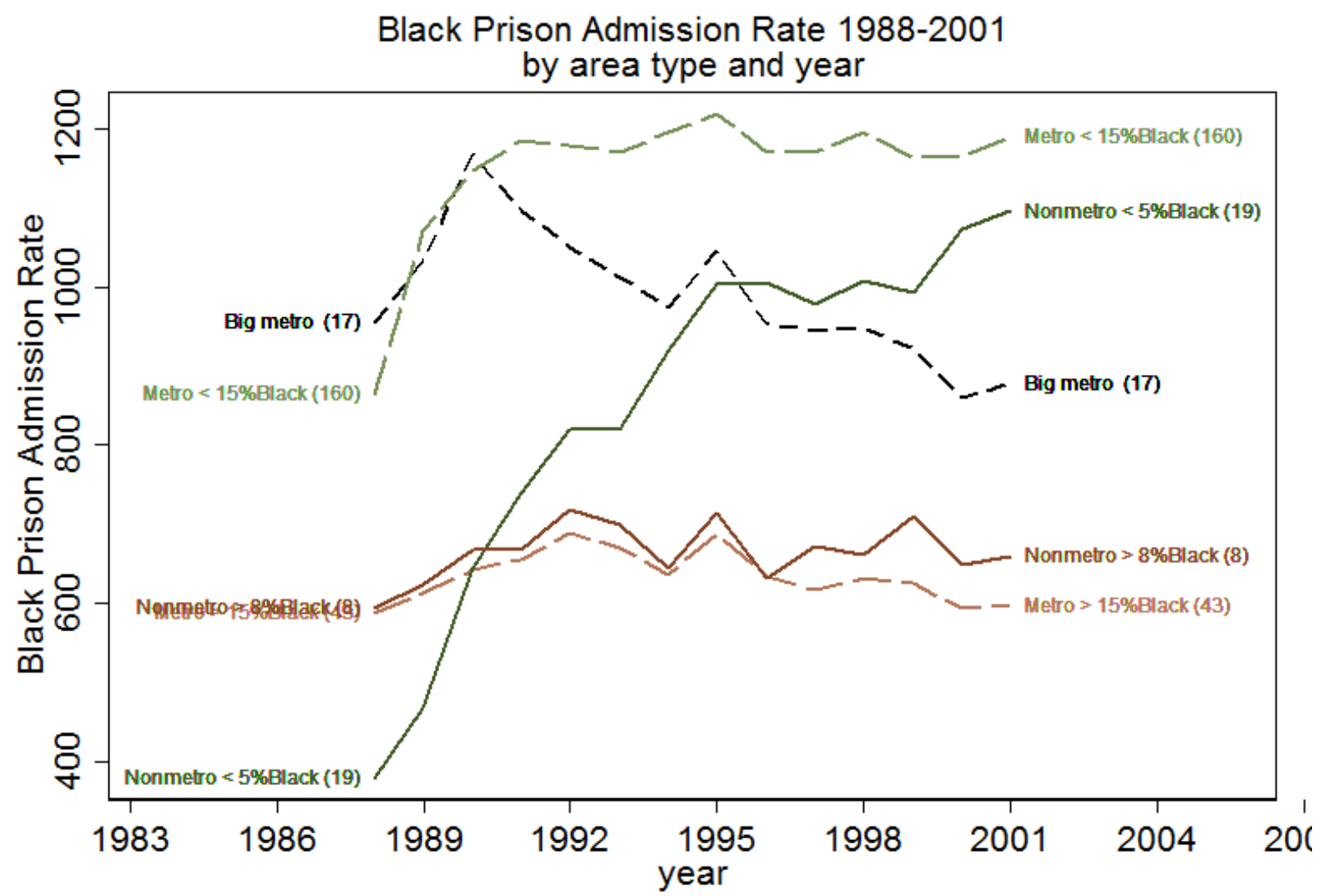

Metro areas and non-metro state balances for 28 states with complete data. N's in labels. 
Figure 5

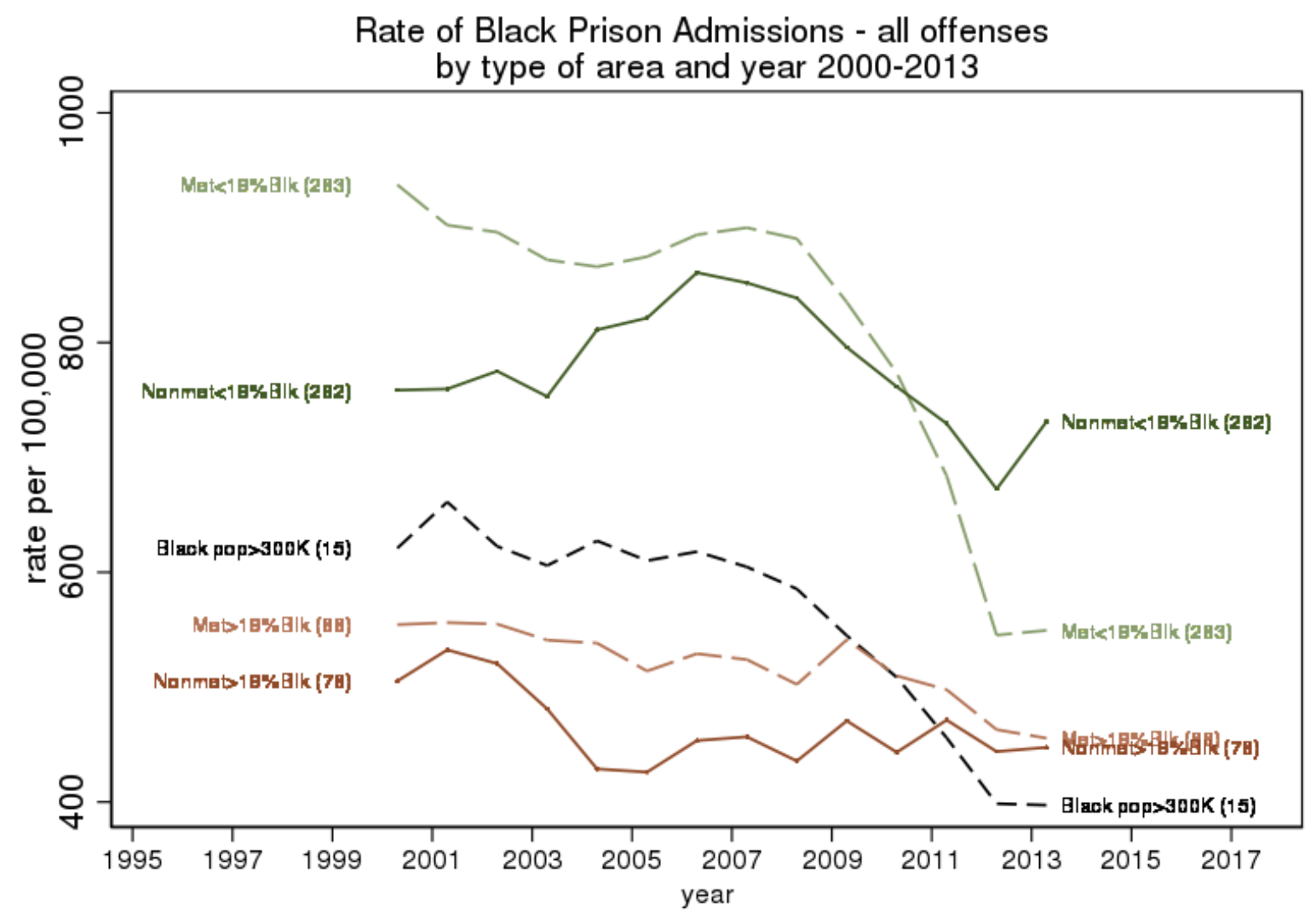

726 county groups in 32 states with complete data 2000-2013 
Figure 6

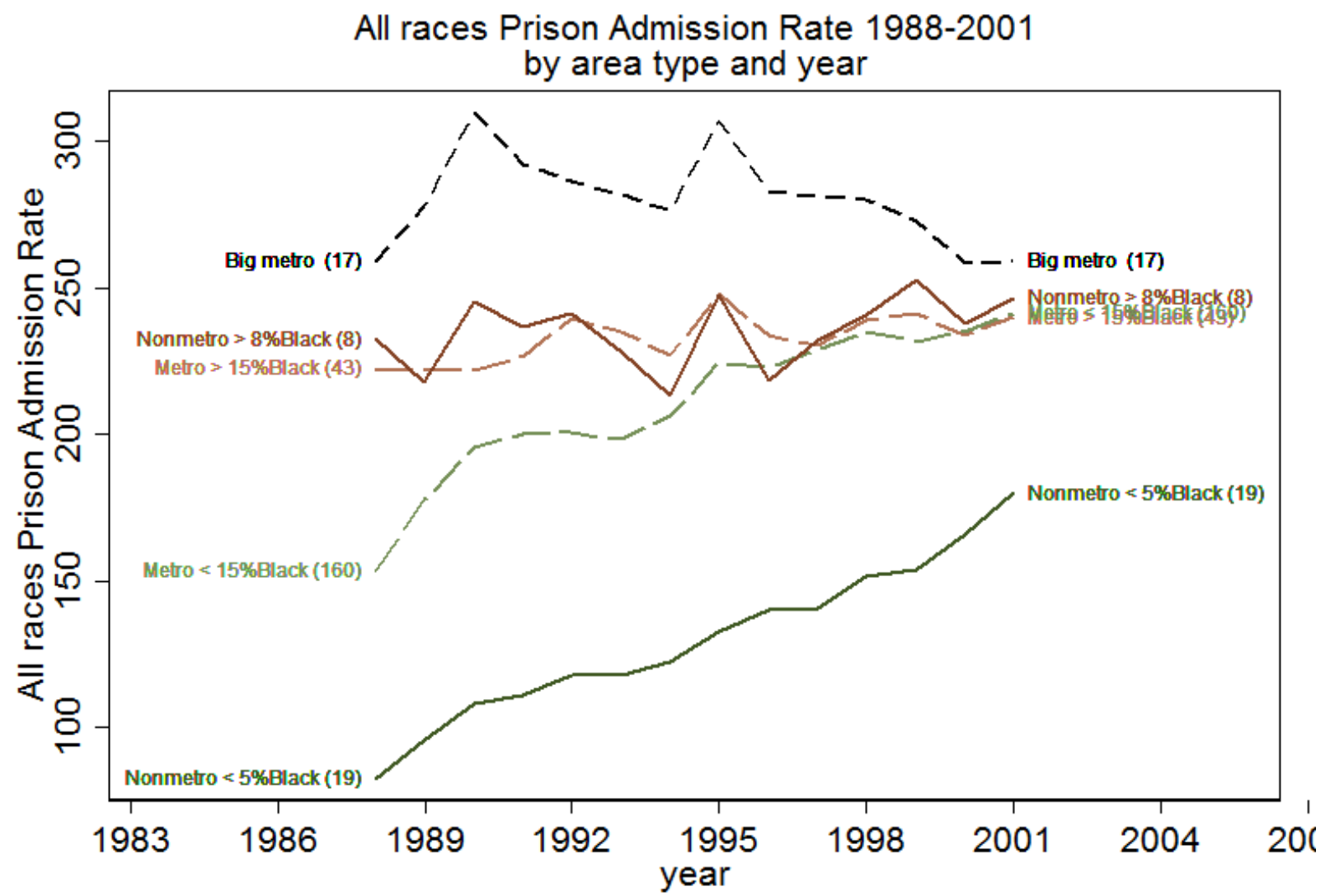

Metro areas and non-metro state balances for 28 states with complete data. N's in labels. 
Figure 7

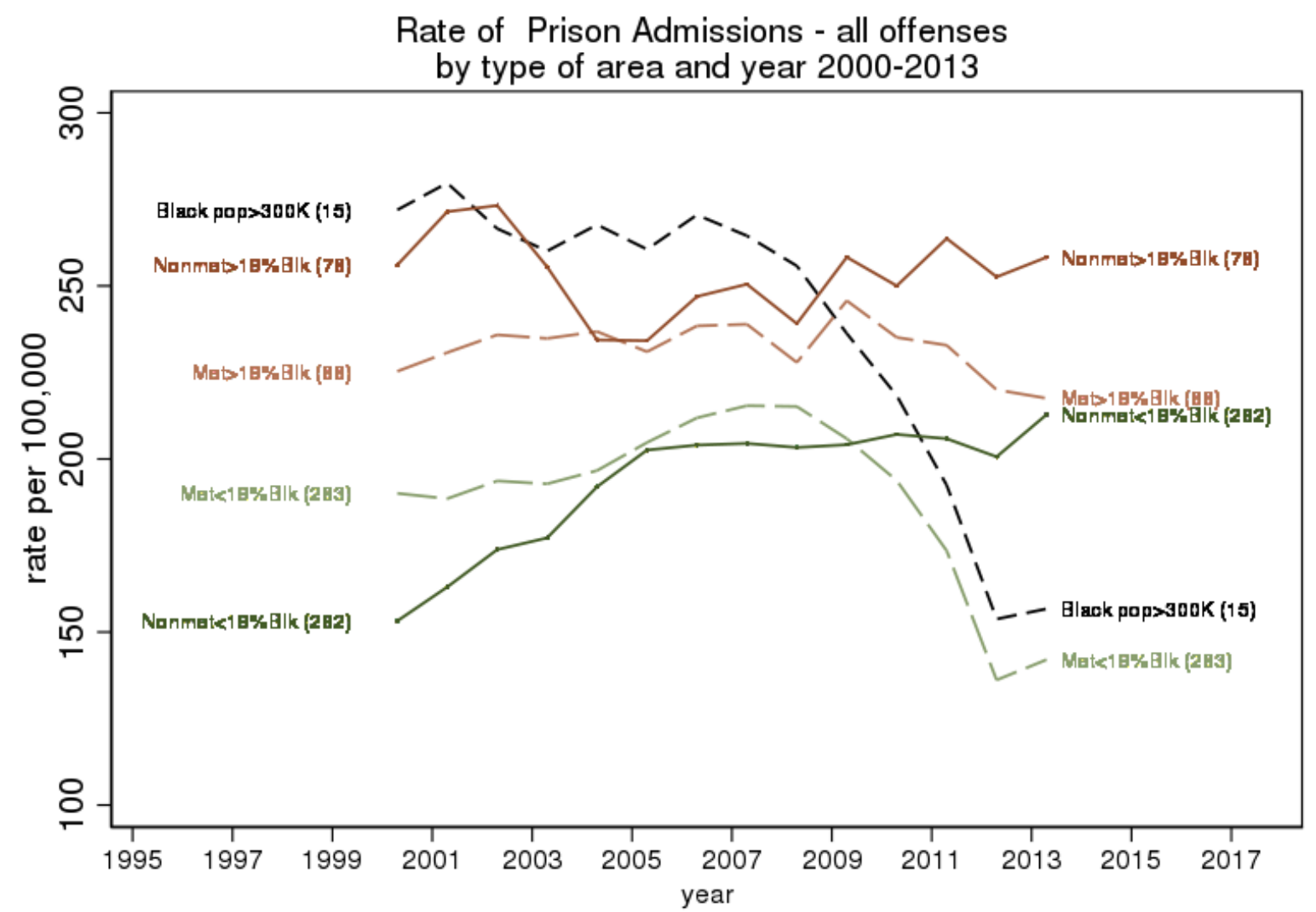

726 county groups in 32 states with complete data $2000-2013$ 
Figure 8

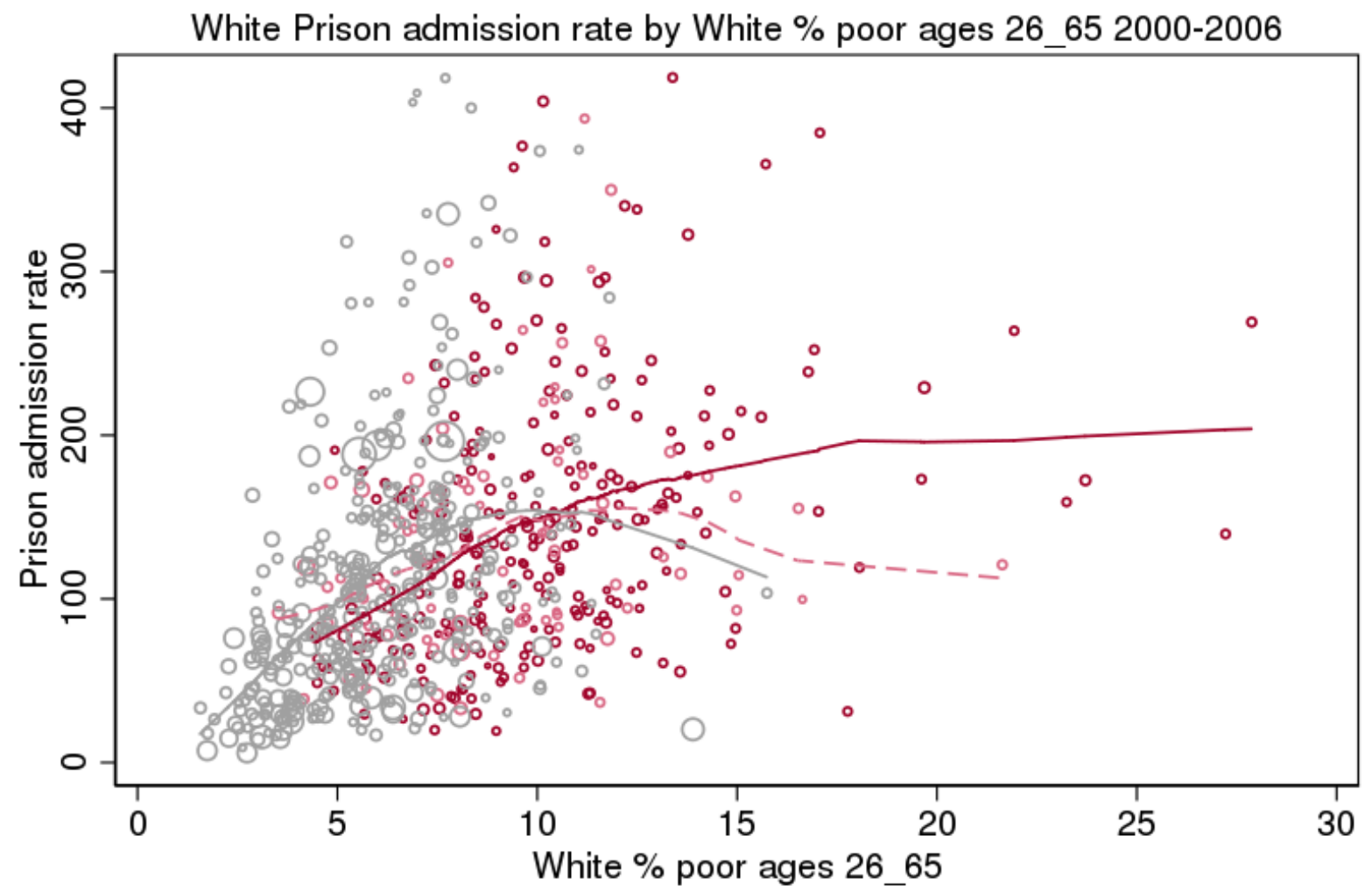

726 county groups. Signed $R^{2}$ : urban (gray) 0.20 , rural (red) 0.13 , mixed (pink) 0.05 .

Marker size proportional to White population, correlations \& trend weighted by population.

Rates greater than 3 standard deviations above the mean are dropped from the graph 
Figure 9

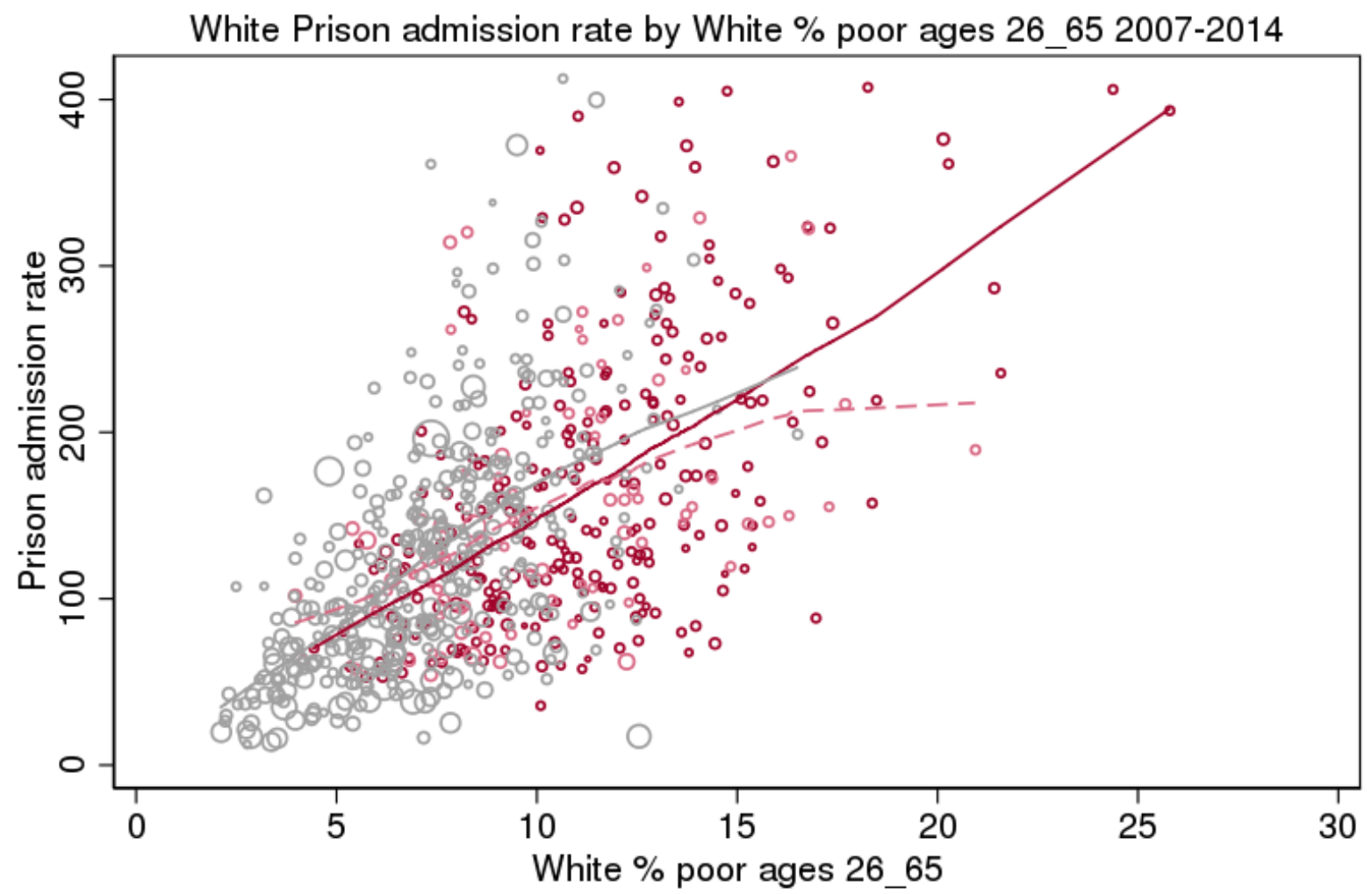

726 county groups. Signed $R^{2}$ : urban (gray) 0.30 , rural (red) 0.34 , mixed (pink) 0.19 . Marker size proportional to White population, correlations \& trend weighted by population.

Rates greater than 3 standard deviations above the mean are dropped from the graph 


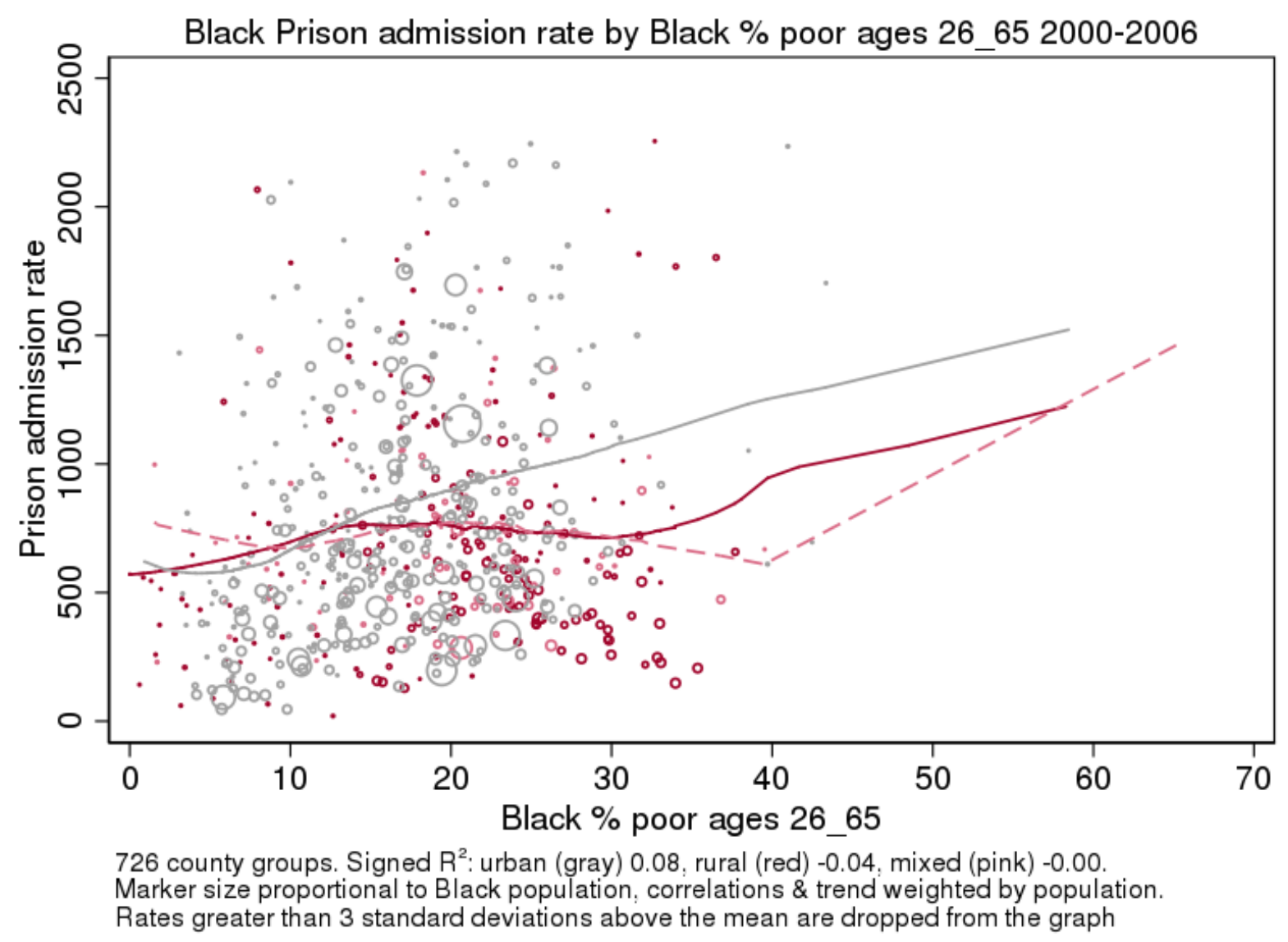


Figure 11

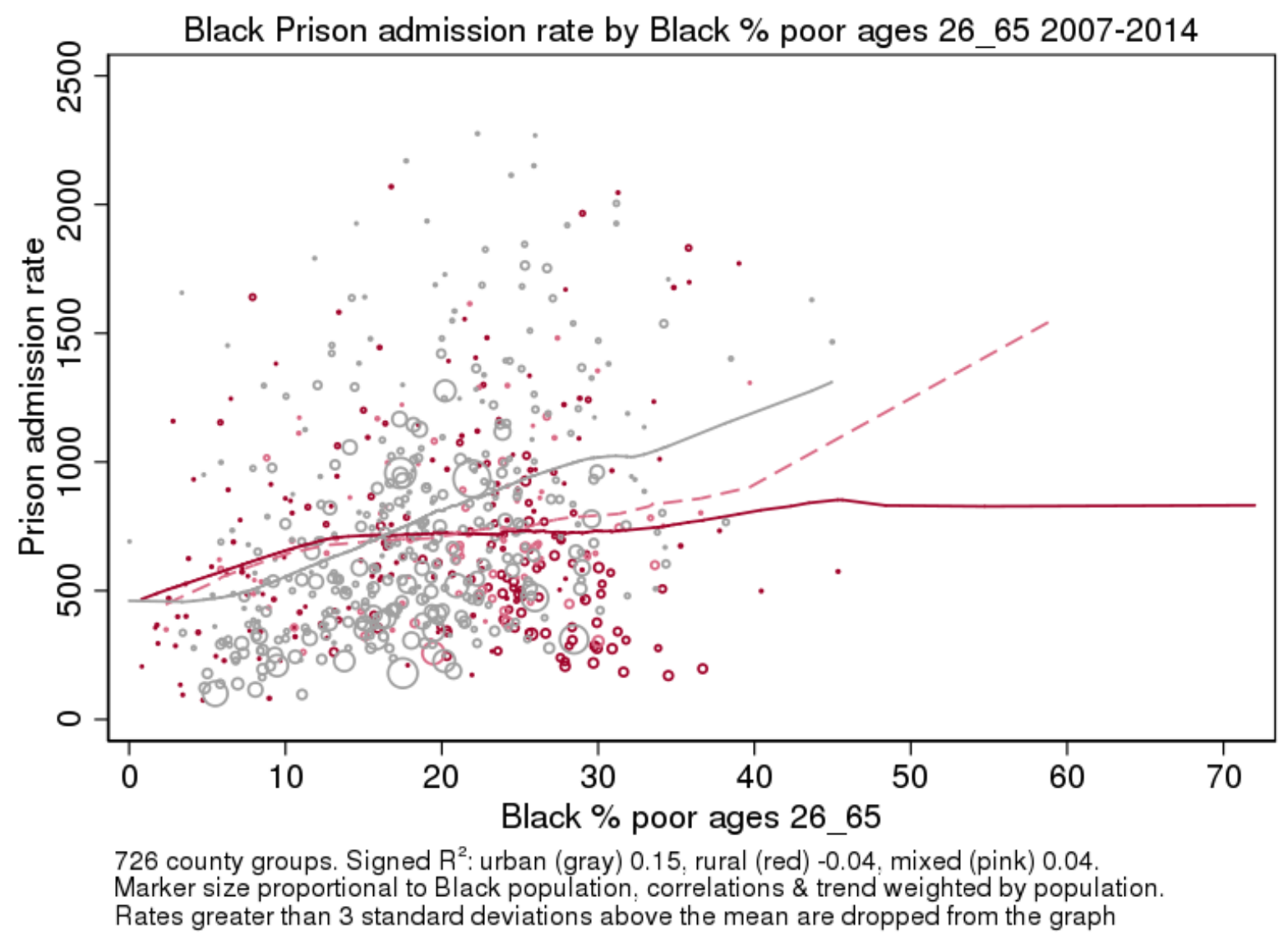


Figure 12

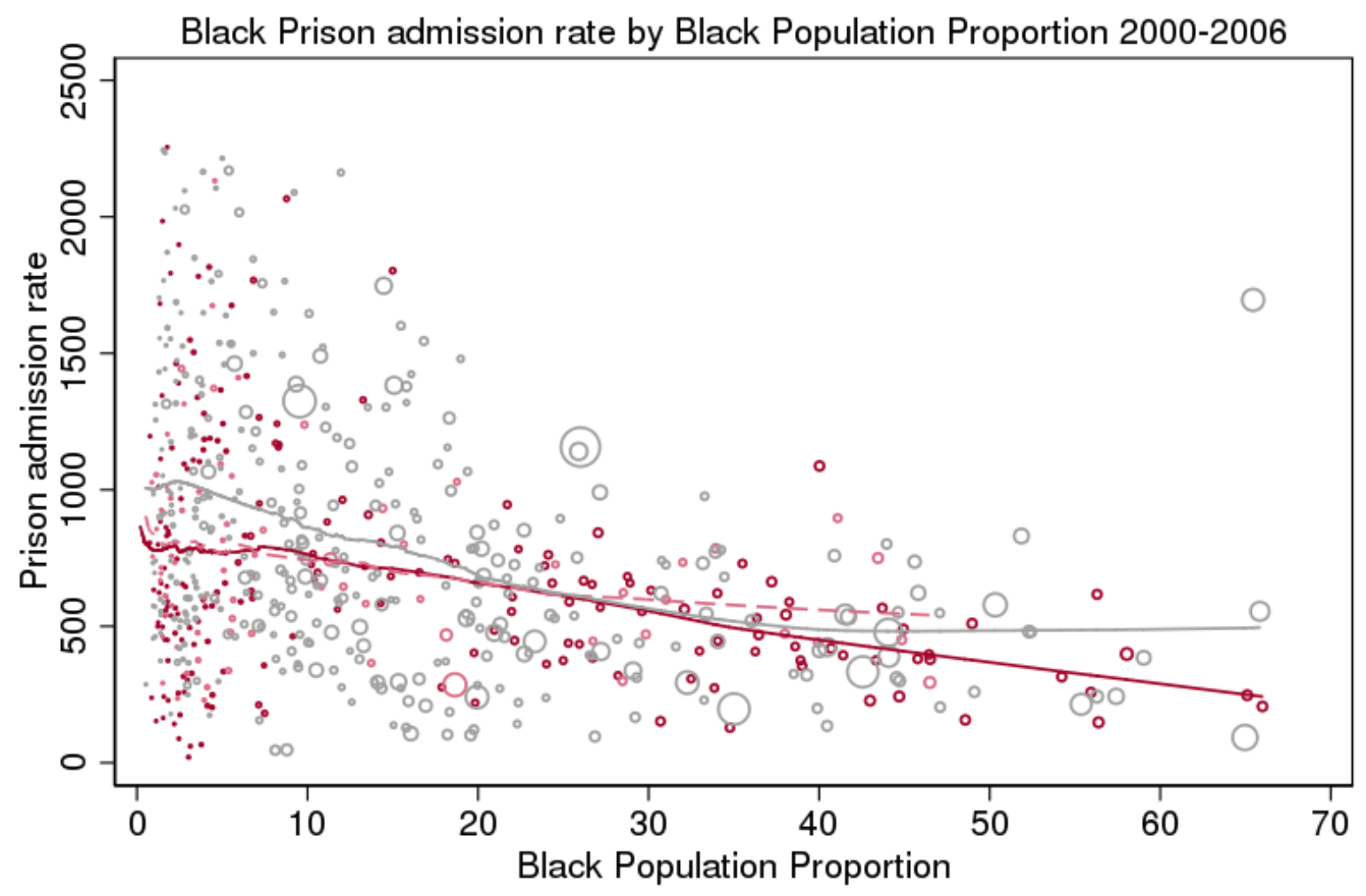

726 county groups. Signed $R^{2}$ : urban (gray) -0.13 , rural (red) -0.28 , mixed (pink) -0.06 .

Marker size proportional to Black population, correlations \& trend weighted by population.

Rates greater than 3 standard deviations above the mean are dropped from the graph 
Figure 13

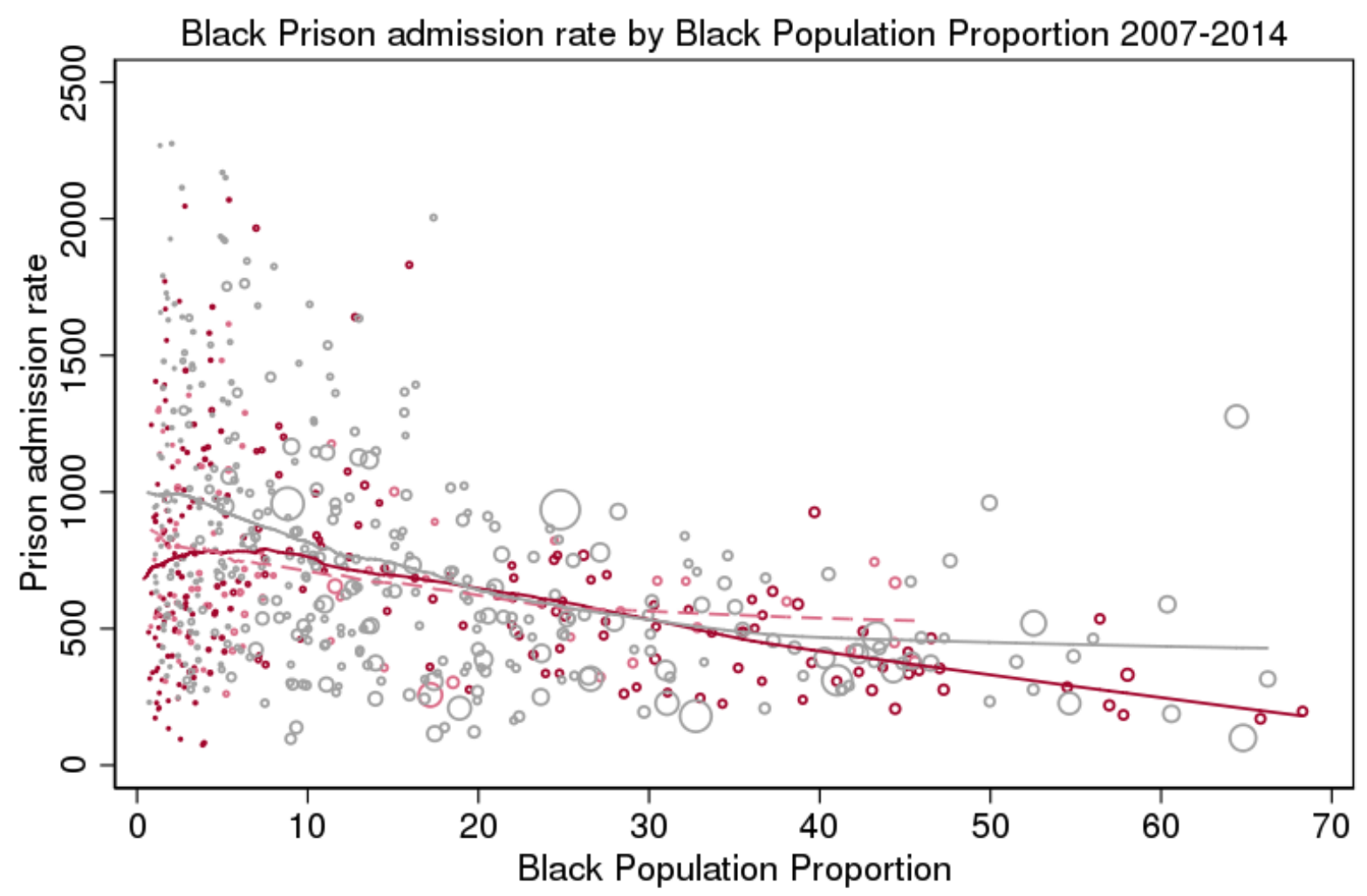

726 county groups. Signed $R^{2}$ : urban (gray) -0.15 , rural (red) -0.35 , mixed (pink) -0.04 .

Marker size proportional to Black population, correlations \& trend weighted by population.

Rates greater than 3 standard deviations above the mean are dropped from the graph 
Figure 14

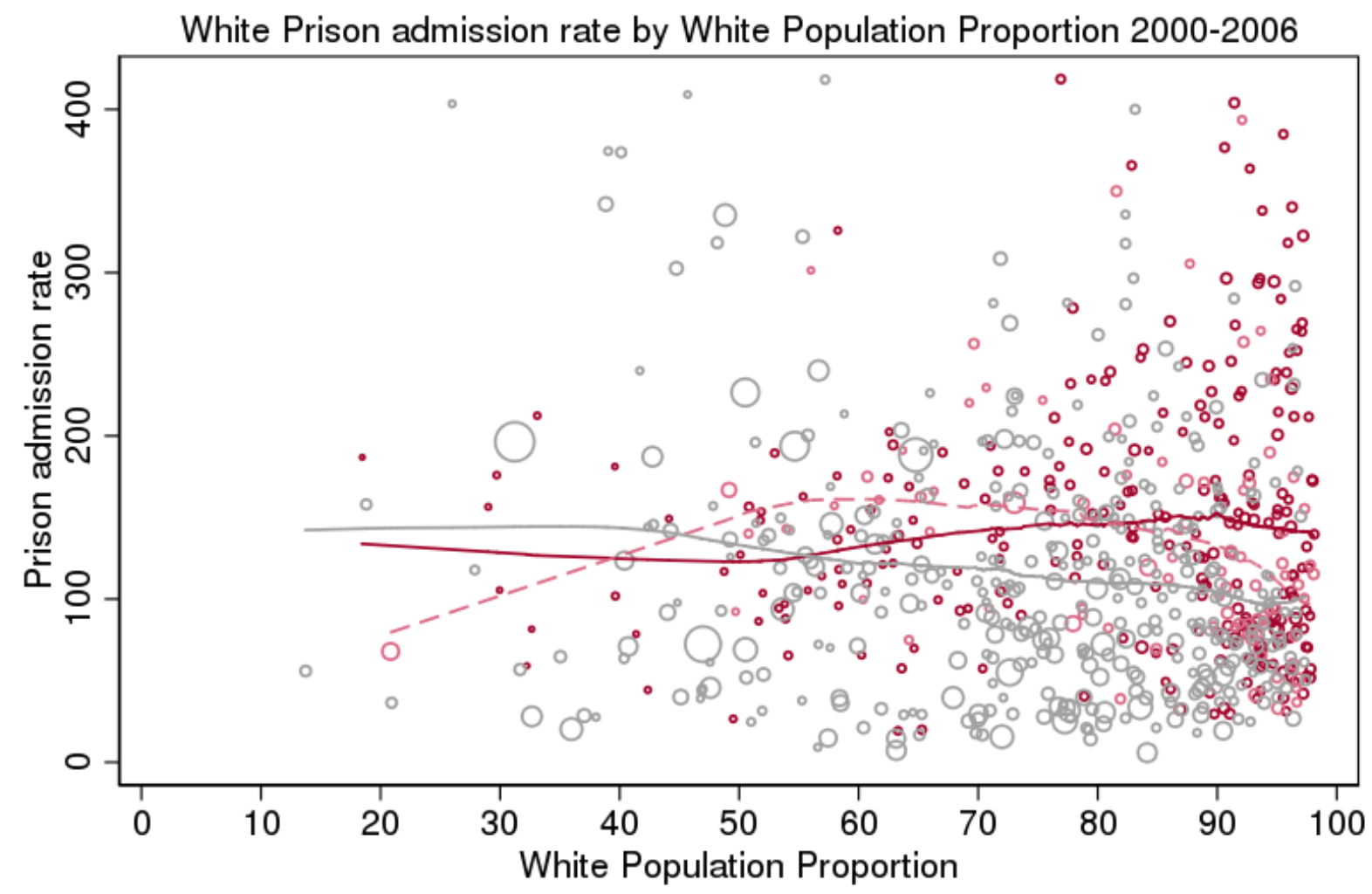

726 county groups. Signed $R^{2}$ : urban (gray) -0.06 , rural (red) -0.00 , mixed (pink) -0.01 .

Marker size proportional to White population, correlations \& trend weighted by population.

Rates greater than 3 standard deviations above the mean are dropped from the graph 
Figure 15

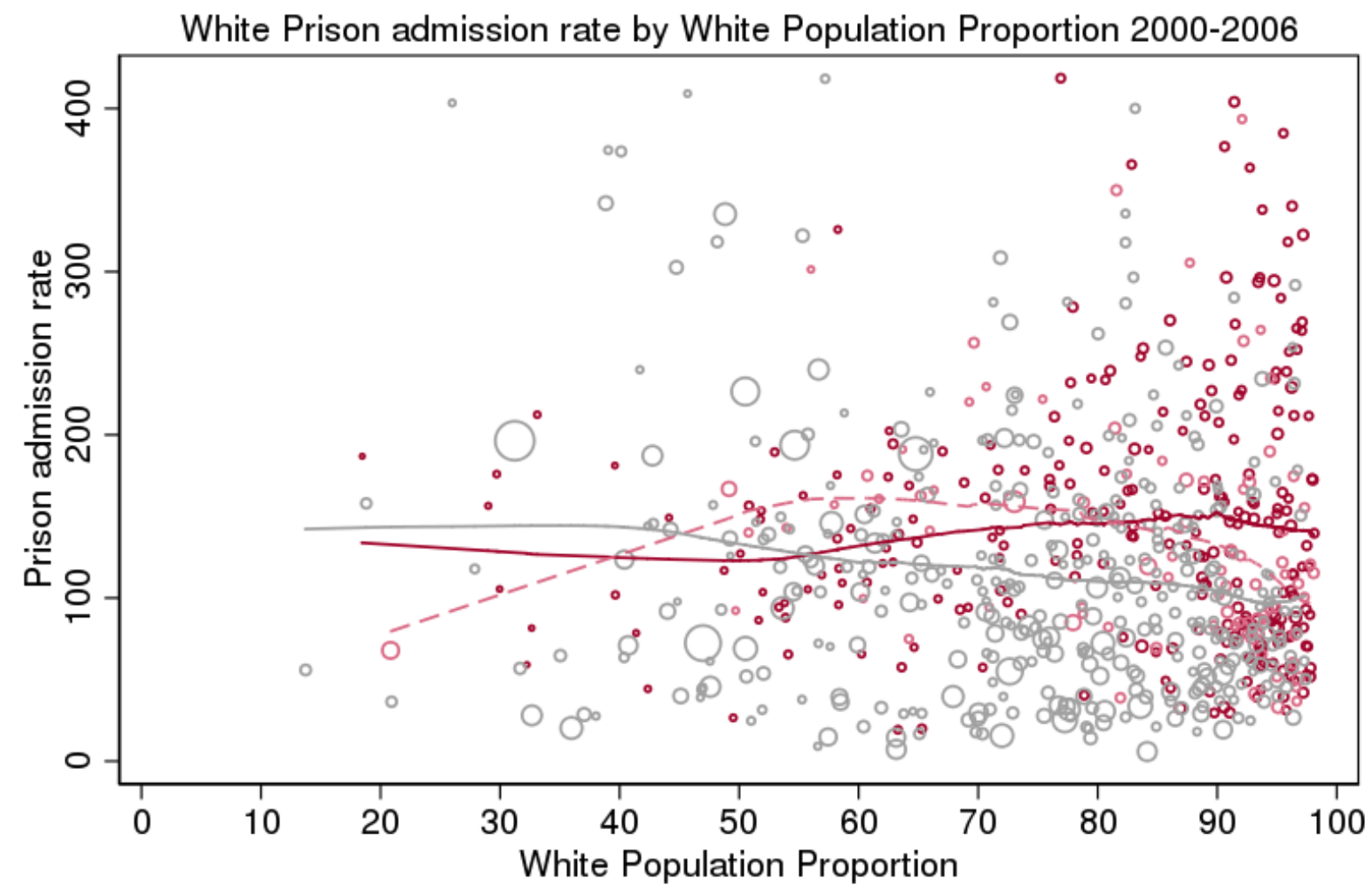

726 county groups. Signed $R^{2}$ : urban (gray) -0.06 , rural (red) -0.00 , mixed (pink) -0.01 .

Marker size proportional to White population, correlations \& trend weighted by population.

Rates greater than 3 standard deviations above the mean are dropped from the graph 
Figure 16

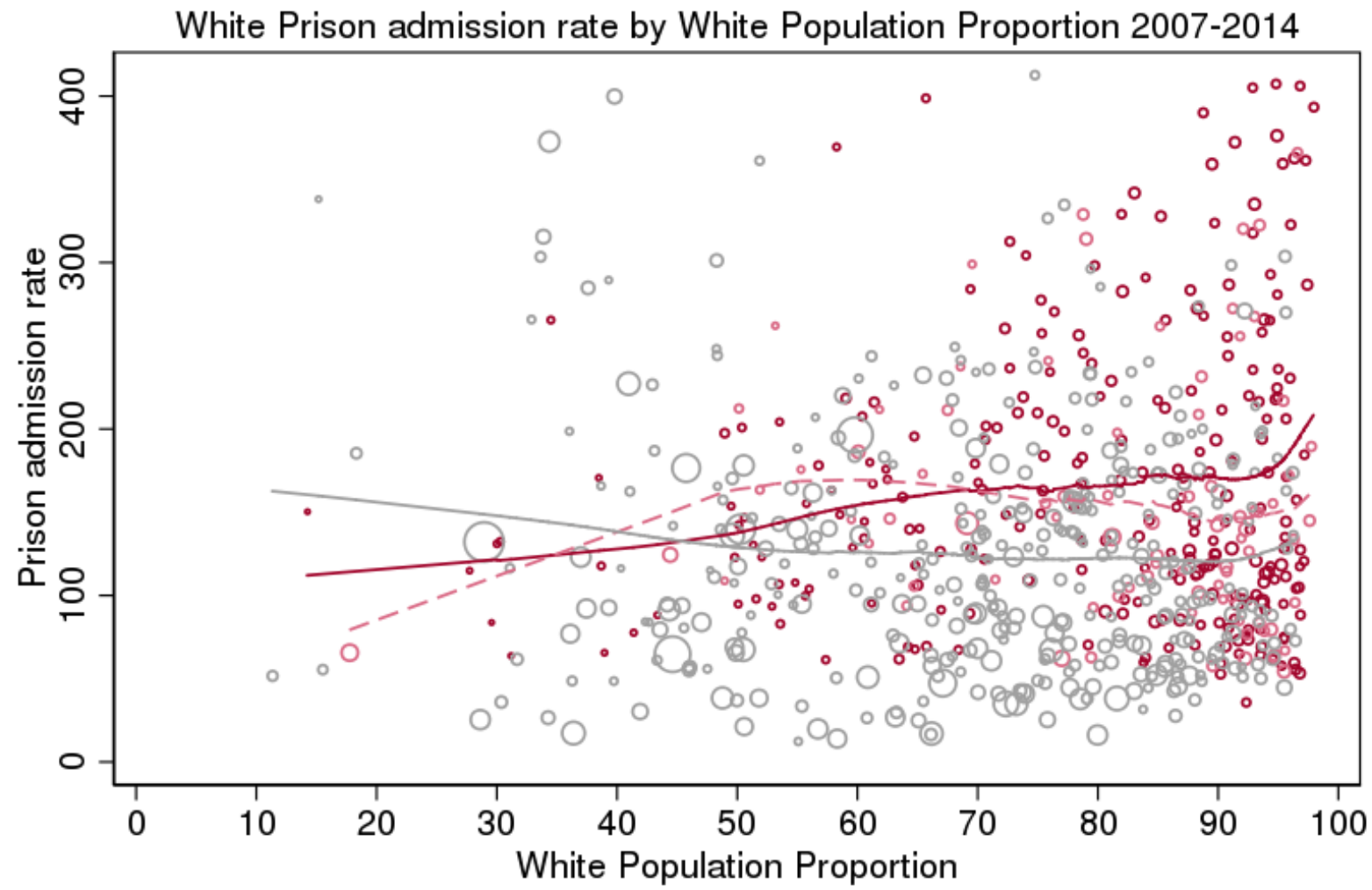

726 county groups. Signed $R^{2}$ : urban (gray) -0.00 , rural (red) 0.01 , mixed (pink) 0.01 .

Marker size proportional to White population, correlations \& trend weighted by population.

Rates greater than 3 standard deviations above the mean are dropped from the graph 
Figure 17

White change in sqrt prison admission rate 2000-2006 to 2007-2013 by lagged percent less than HS educ. ages 26-65

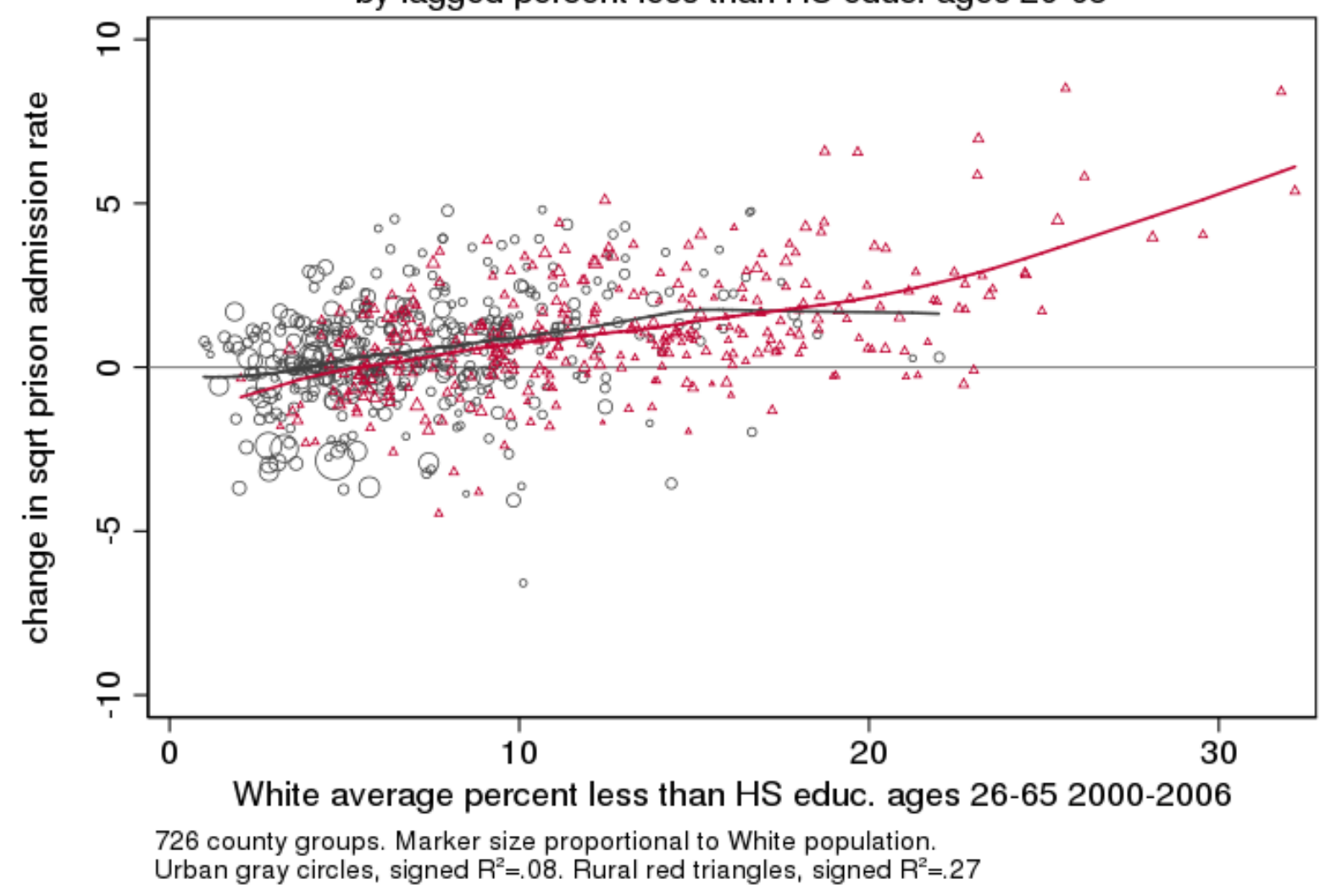


Figure 18

Black change in sqrt prison admission rate 2000-2006 to 2007-2013 by lagged percent less than HS educ. ages 26-65

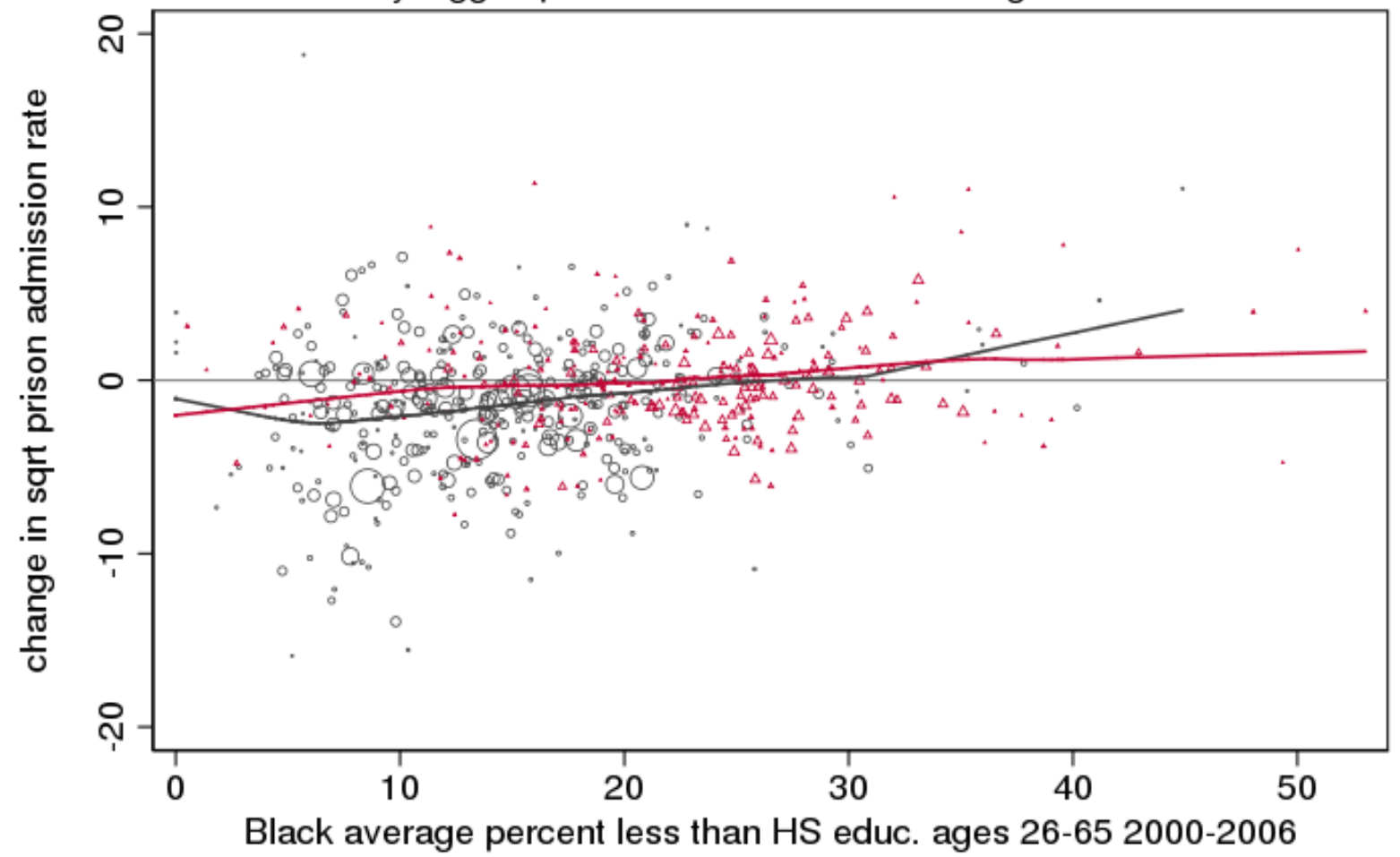

726 county groups. Marker size proportional to Black population.

Urban gray circles, signed $R^{2}=05$. Rural red triangles, signed $R^{2}=.03$ 
Figure 19

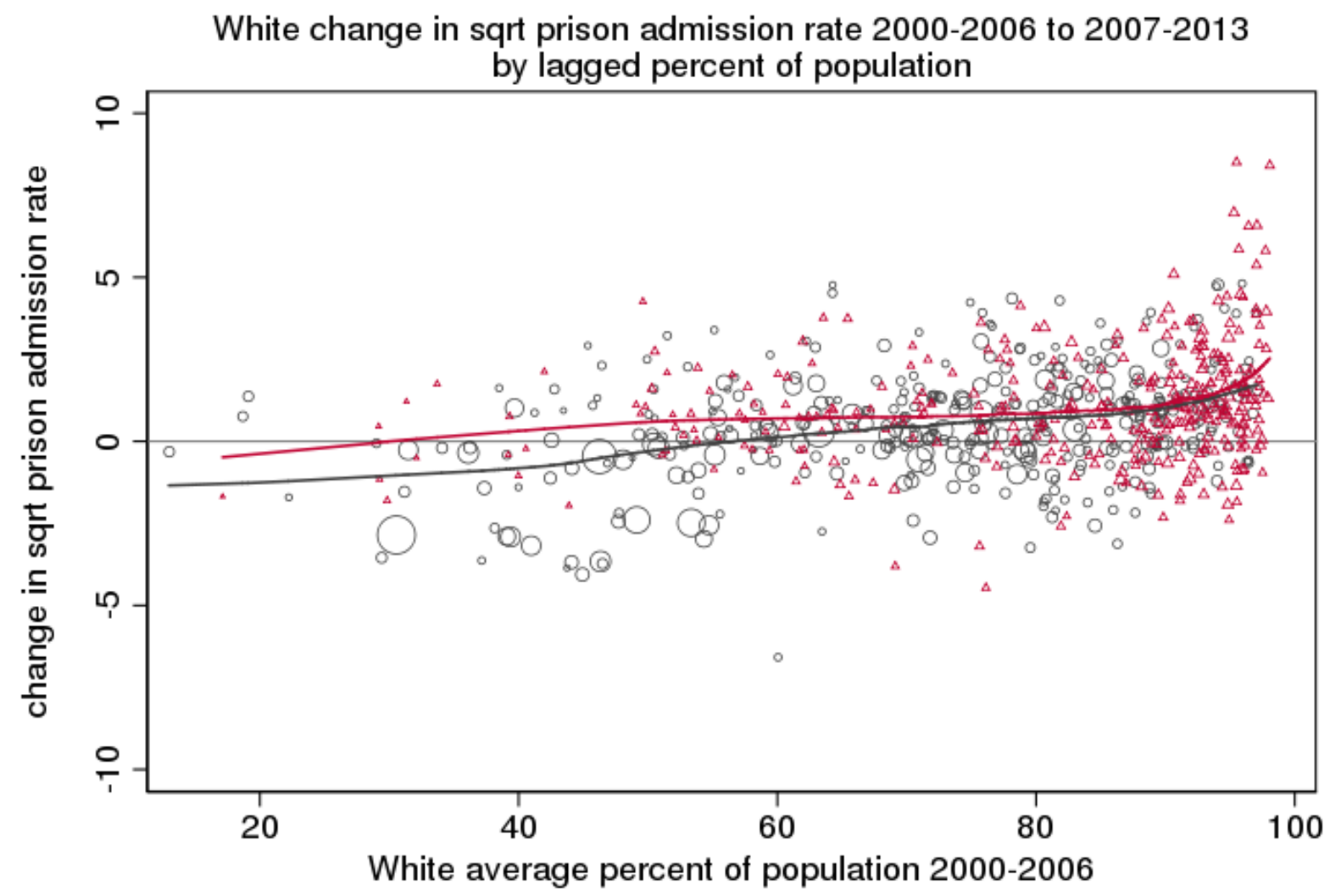

726 county groups. Marker size proportional to White population.

Urban gray circles, signed $\mathrm{R}^{2}=1$. Rural red triangles, signed $\mathrm{R}^{2}=.04$ 
Figure 20

Black change in sqrt prison admission rate 2000-2006 to 2007-2013

by lagged percent of population

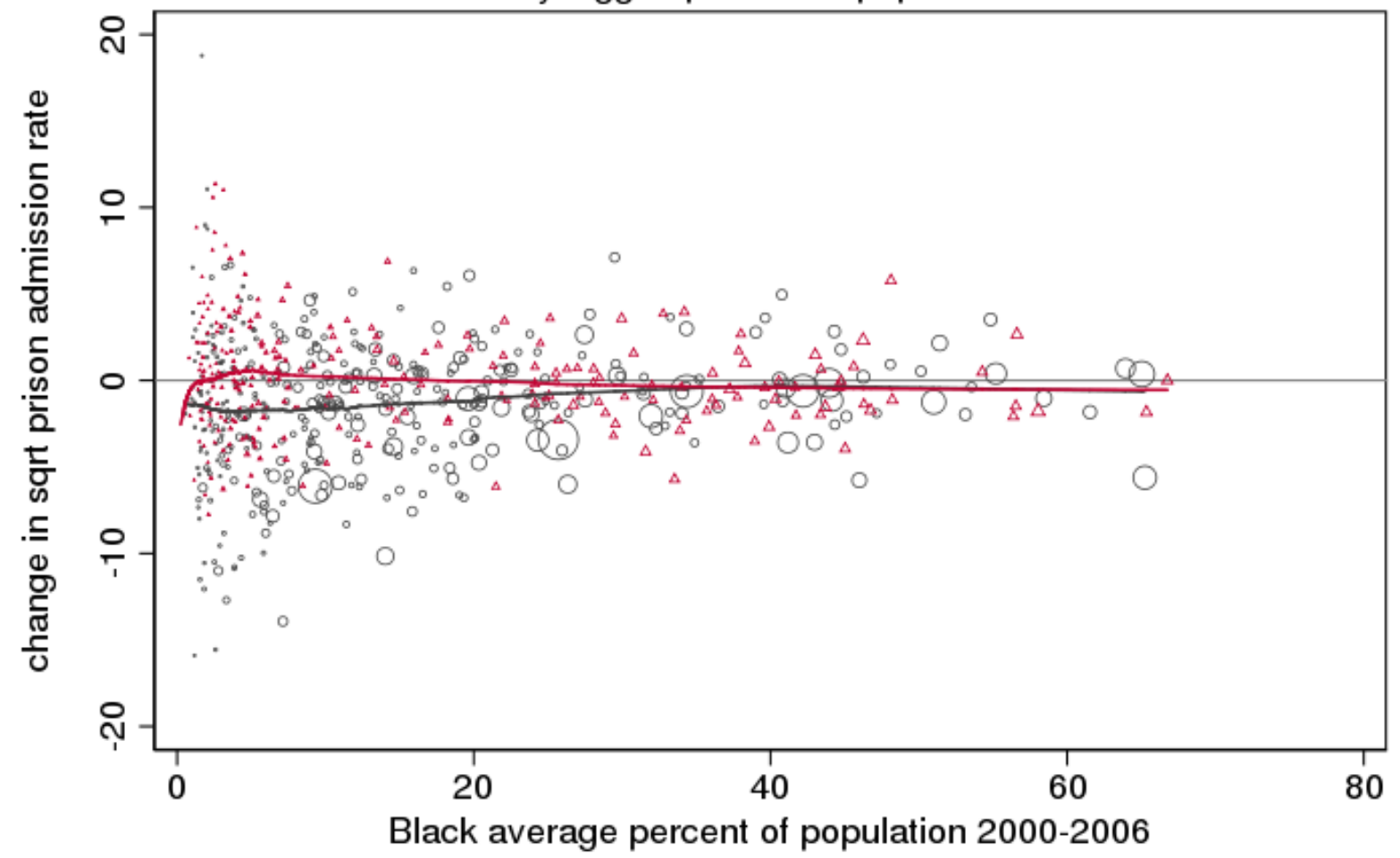

726 county groups. Marker size proportional to Black population.

Urban gray circles, signed $R^{2}=01$. Rural red triangles, signed $R^{2}=0$ 
Appendix A: Average area type trends and scatterplots

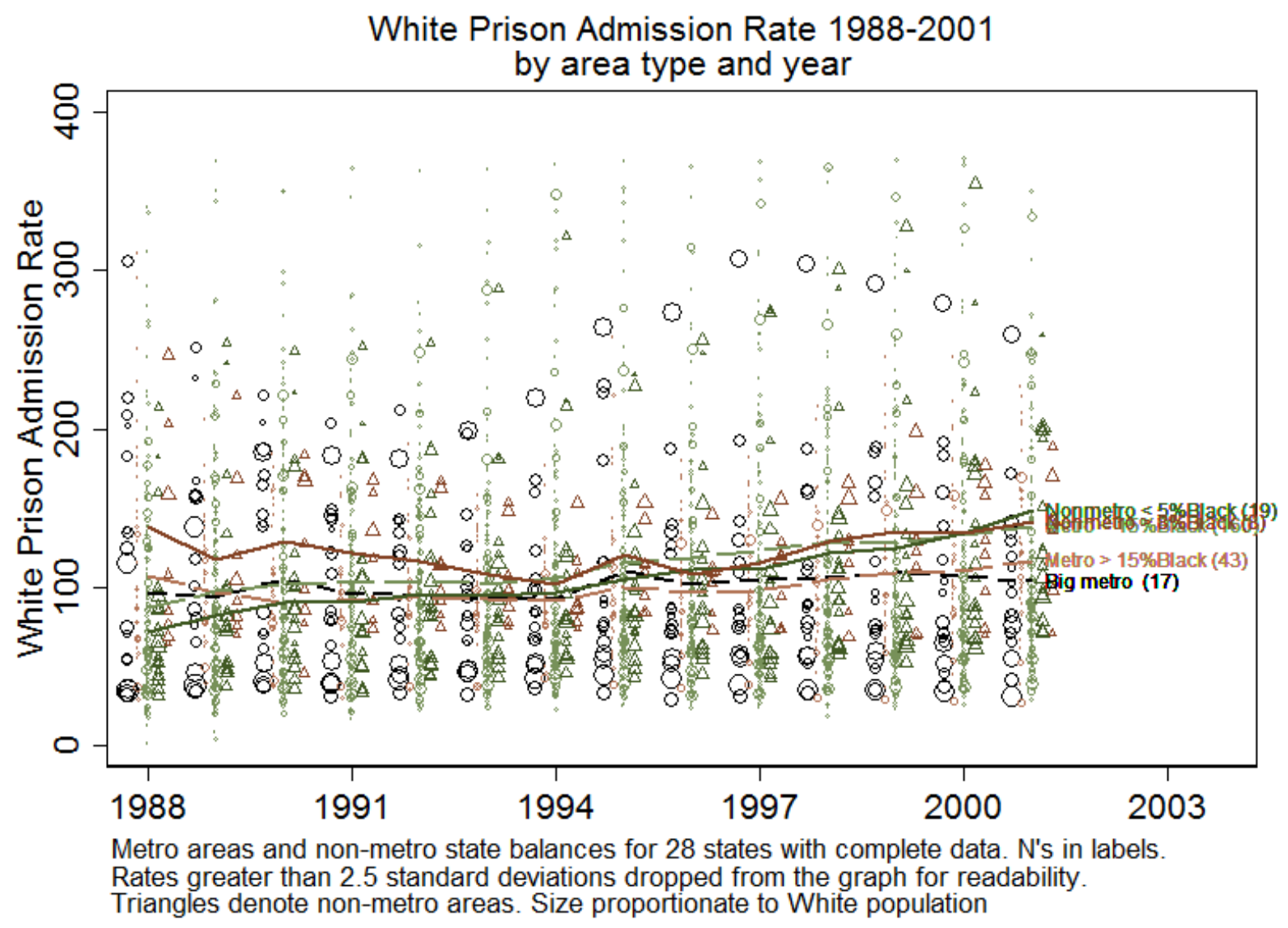




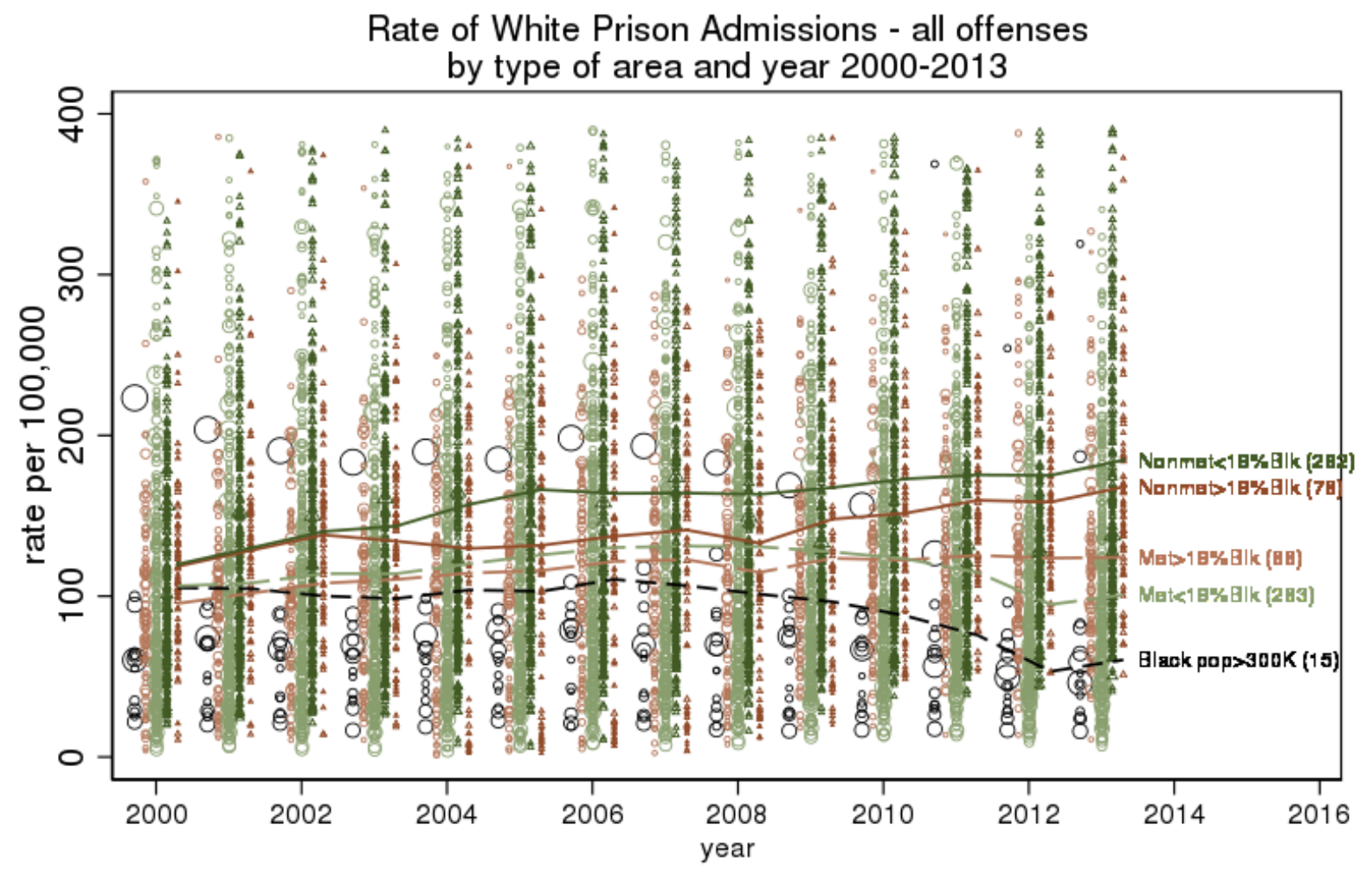

Rates more than 2.5 standard deviations from mean truncated from graph.

Triangles are non-metro areas. Marker size proportionate to White population.

726 county groups in 32 states with complete data 2000-2013 


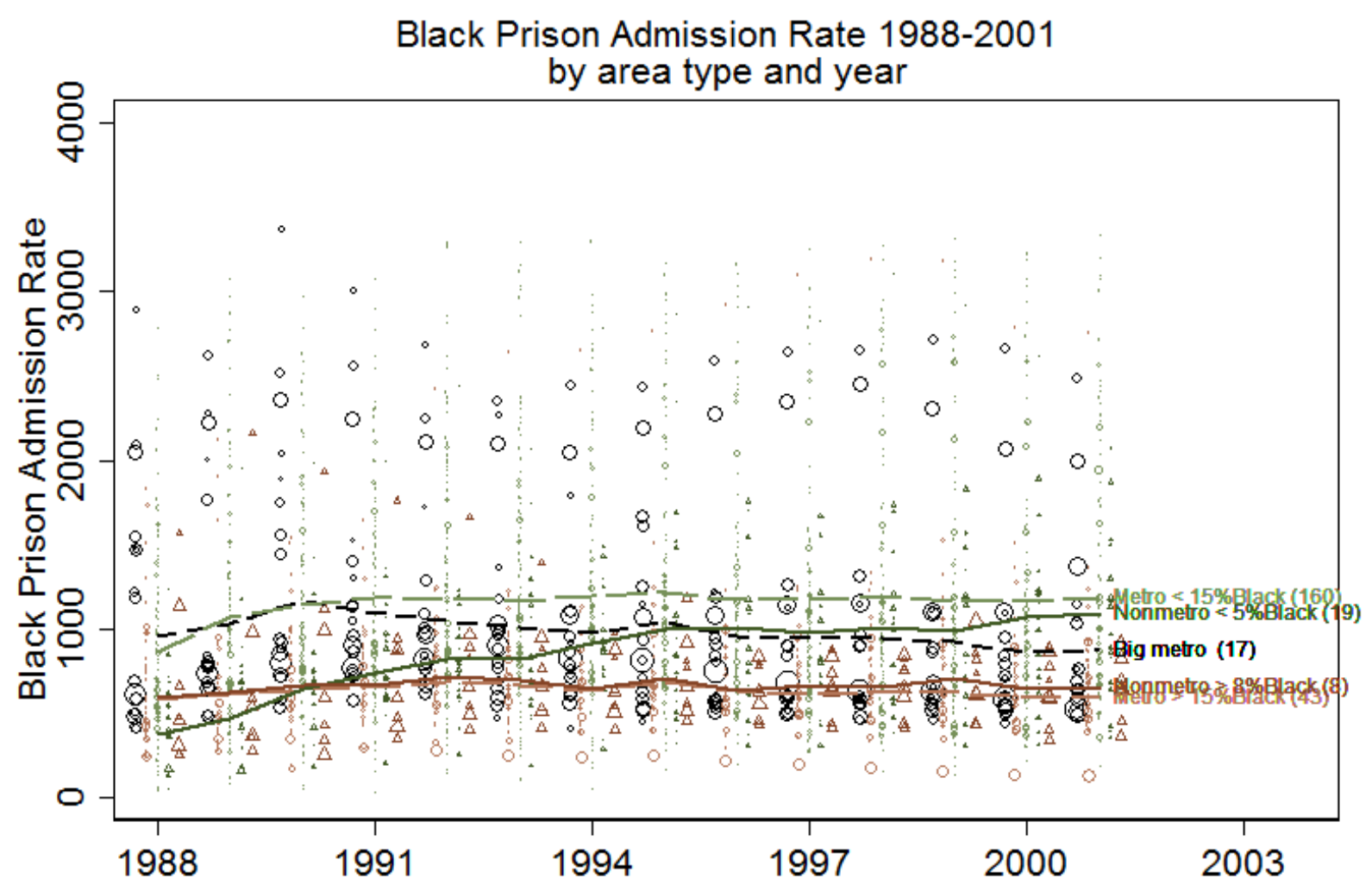

Metro areas and non-metro state balances for 28 states with complete data. N's in labels. Rates greater than 2.5 standard deviations dropped from the graph for readability.

Triangles denote non-metro areas. Size proportionate to Black population 


\section{Rate of Black Prison Admissions - all offenses}

by type of area and year 2000-2013

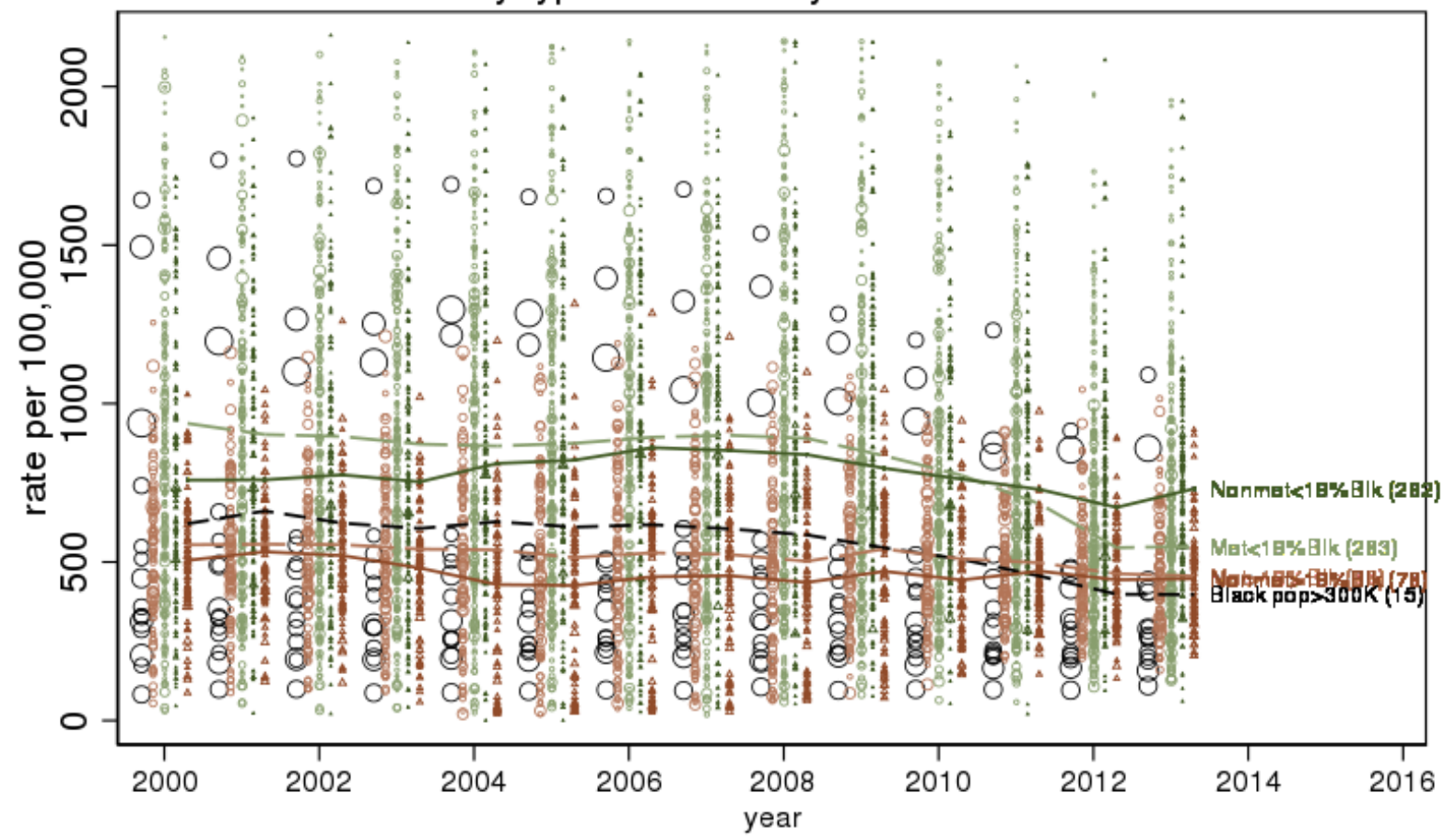

Rates more than 2.5 standard deviations from mean truncated from graph.

Triangles are non-metro areas. Marker size proportionate to Black population.

726 county groups in 32 states with complete data 2000-2013 


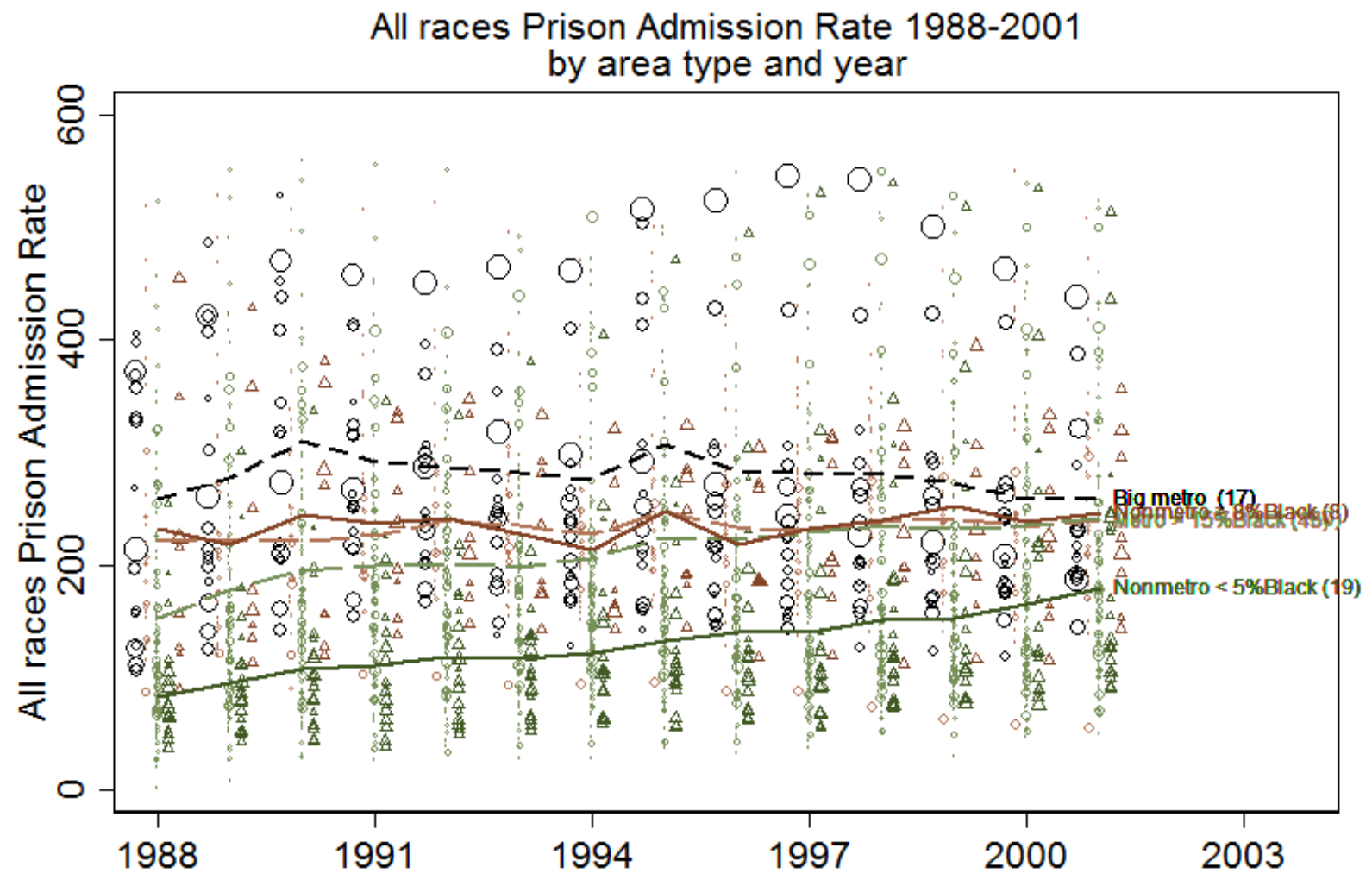

Metro areas and non-metro state balances for 28 states with complete data. N's in labels. Rates greater than 2.5 standard deviations dropped from the graph for readability.

Triangles denote non-metro areas. Size proportionate to All races population 


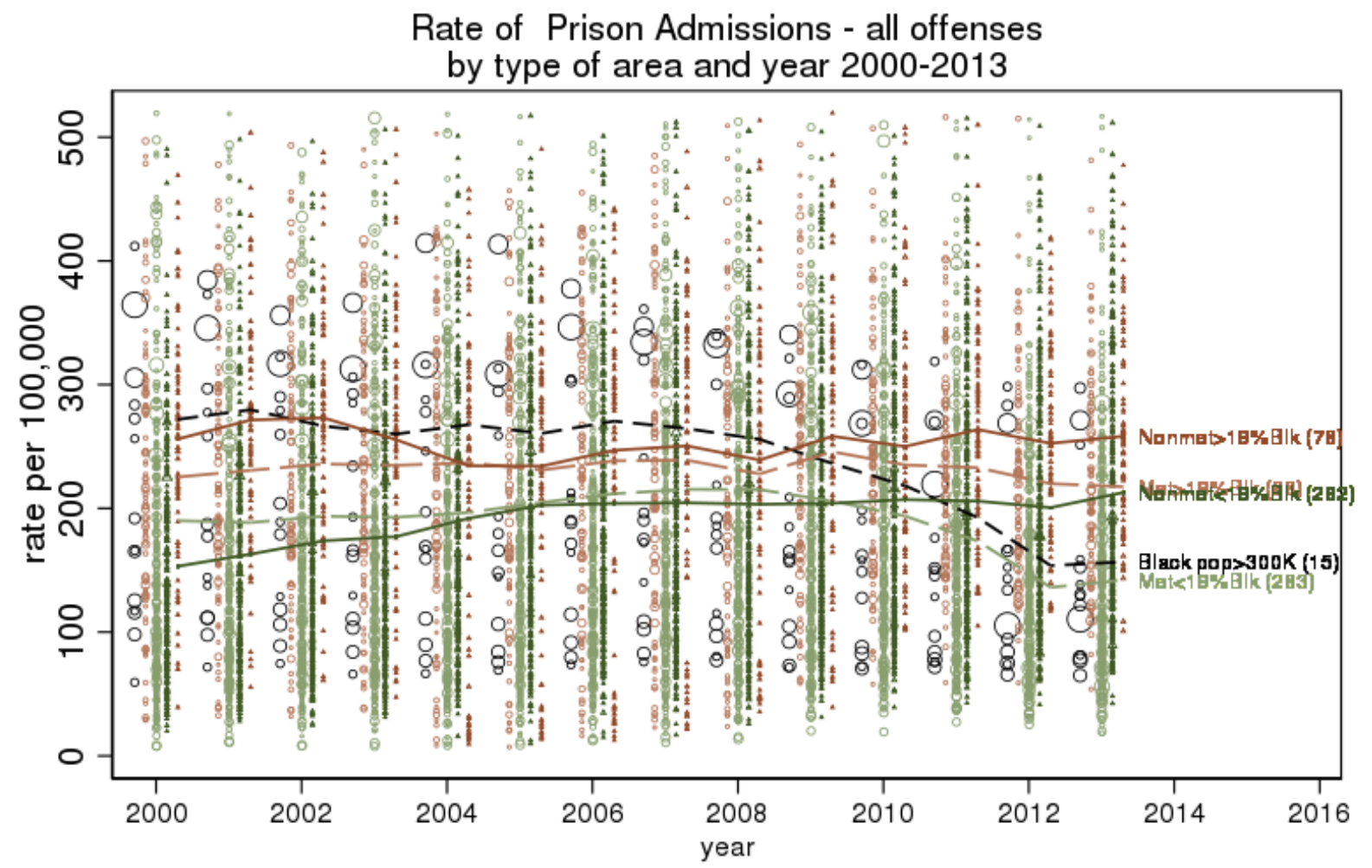

Rates more than 2.5 standard deviations from mean truncated from graph. Triangles are non-metro areas. Marker size proportionate to population.

726 county groups in 32 states with complete data 2000-2013 
Appendix B: Education and incarceration for rural and urban areas

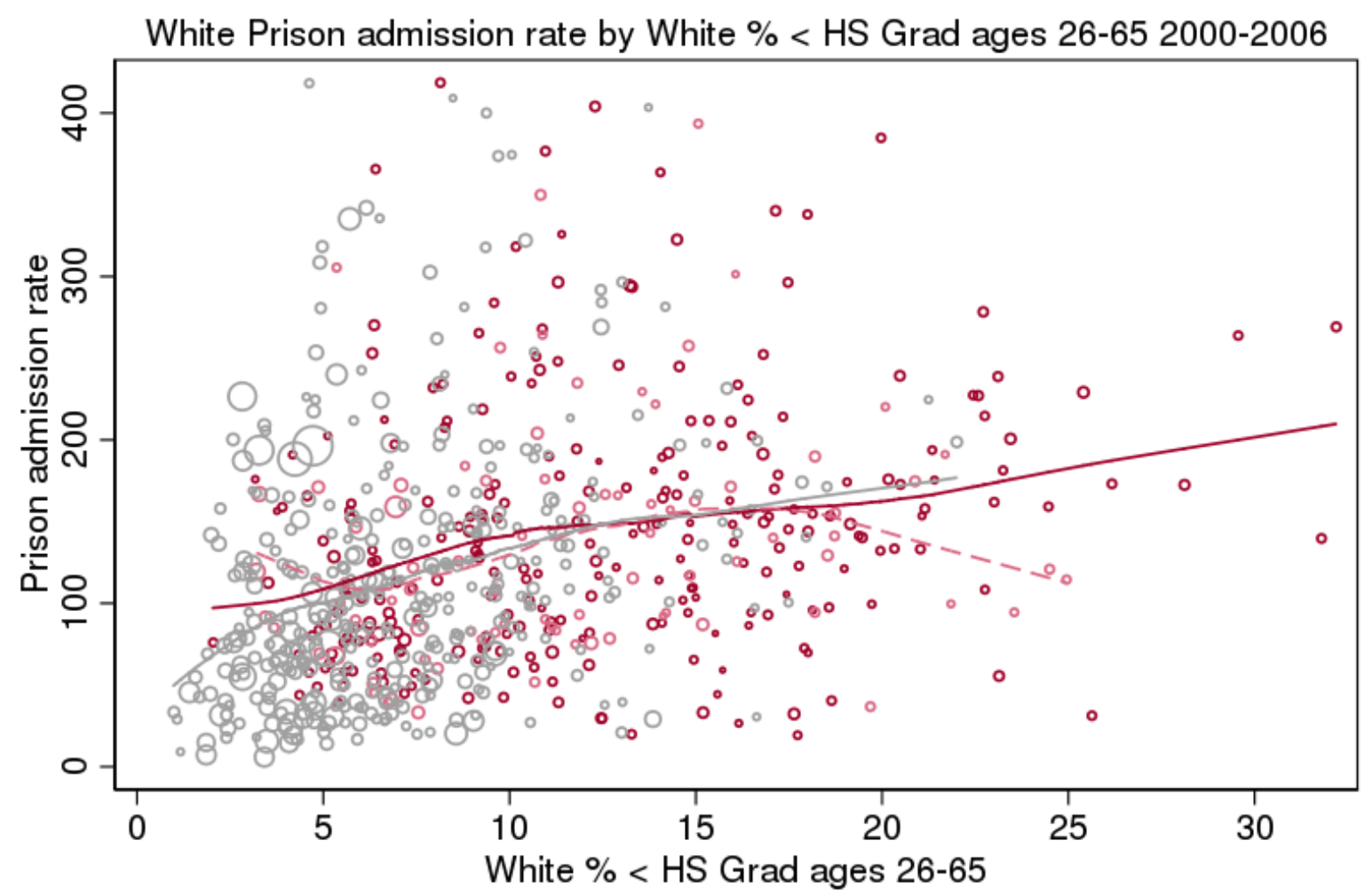

726 county groups. Signed $R^{2}$ : urban (gray) 0.06 , rural (red) 0.06 , mixed (pink) 0.04 . Marker size proportional to White population, correlations \& trend weighted by population. Rates greater than 3 standard deviations above the mean are dropped from the graph 


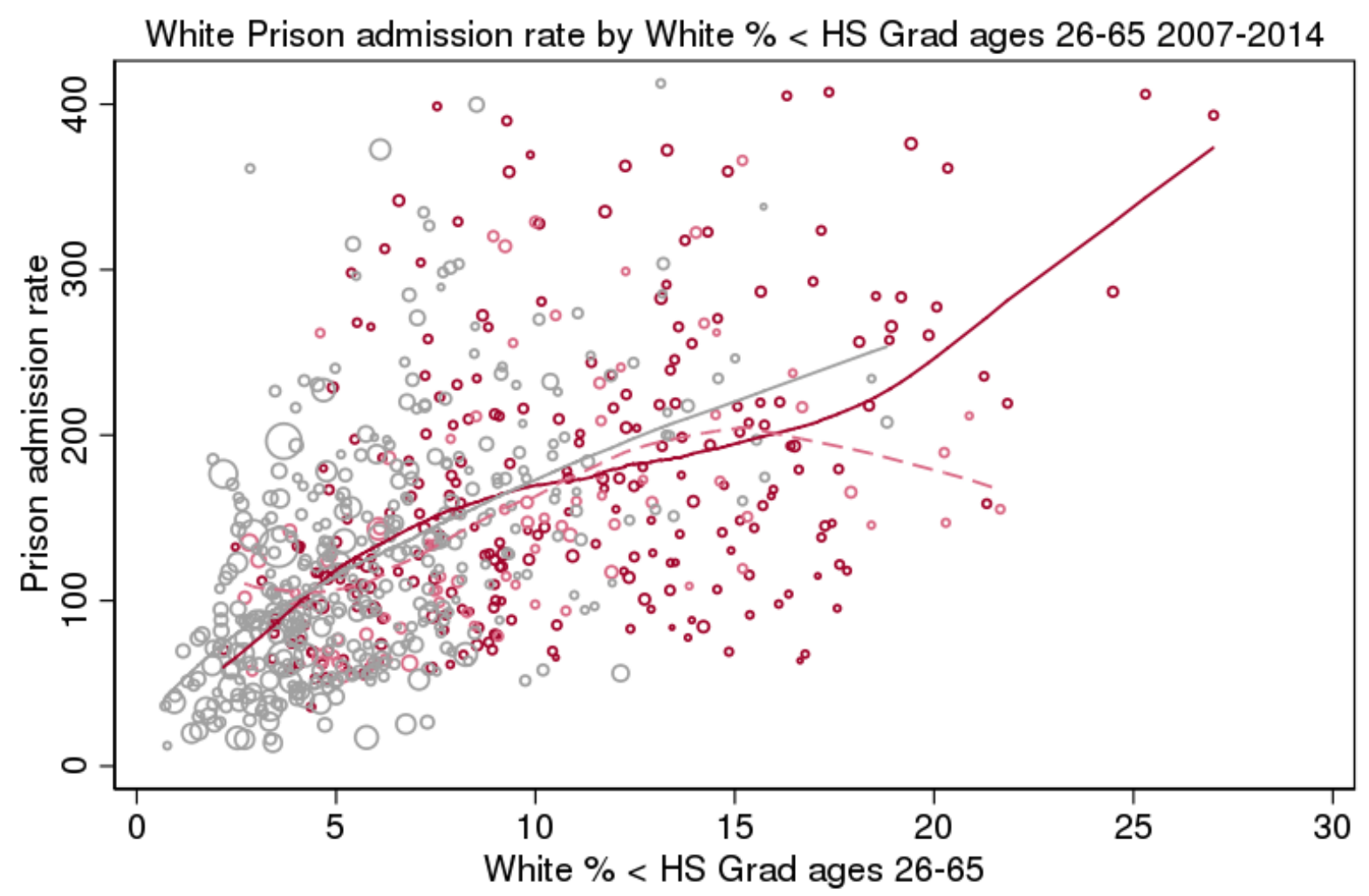

726 county groups. Signed $R^{2}$ : urban (gray) 0.22 , rural (red) 0.28 . mixed (pink) 0.24 . Marker size proportional to White population, correlations \& trend weighted by population. Rates greater than 3 standard deviations above the mean are dropped from the graph 
White Prison admission rate by White \% Coll Grad ages 26-65 2000-2006

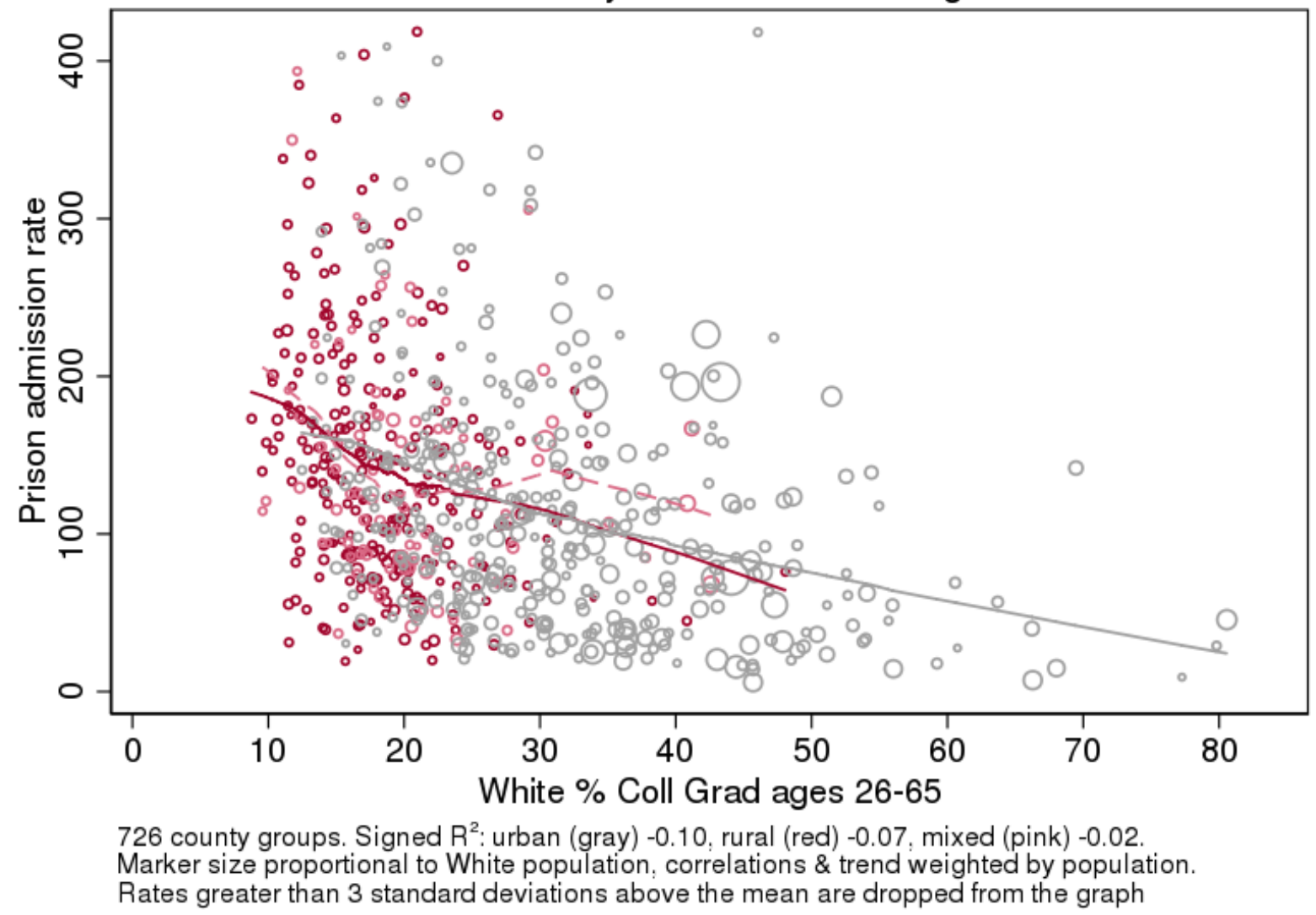


White Prison admission rate by White \% Coll Grad ages 26-65 2007-2014

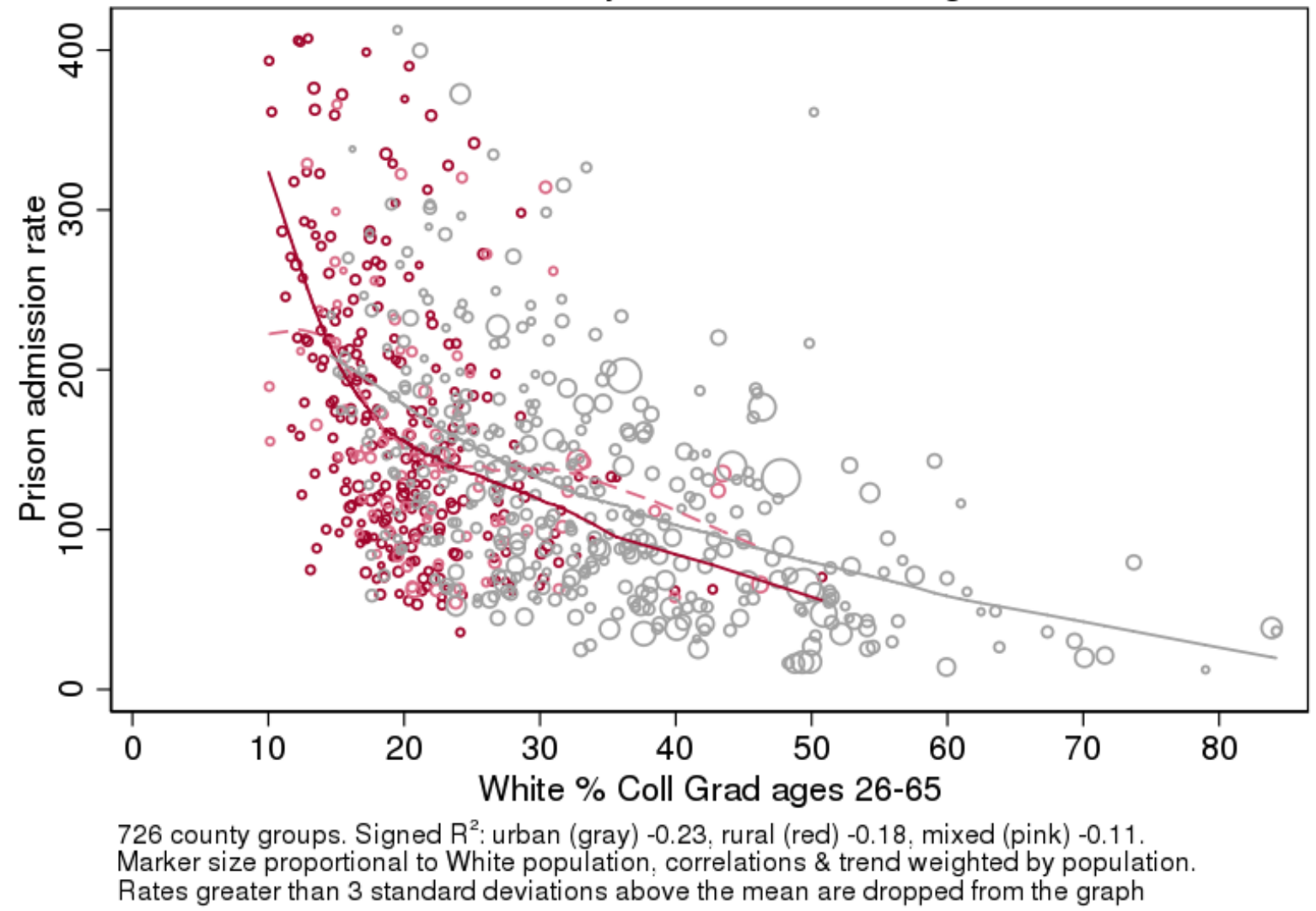




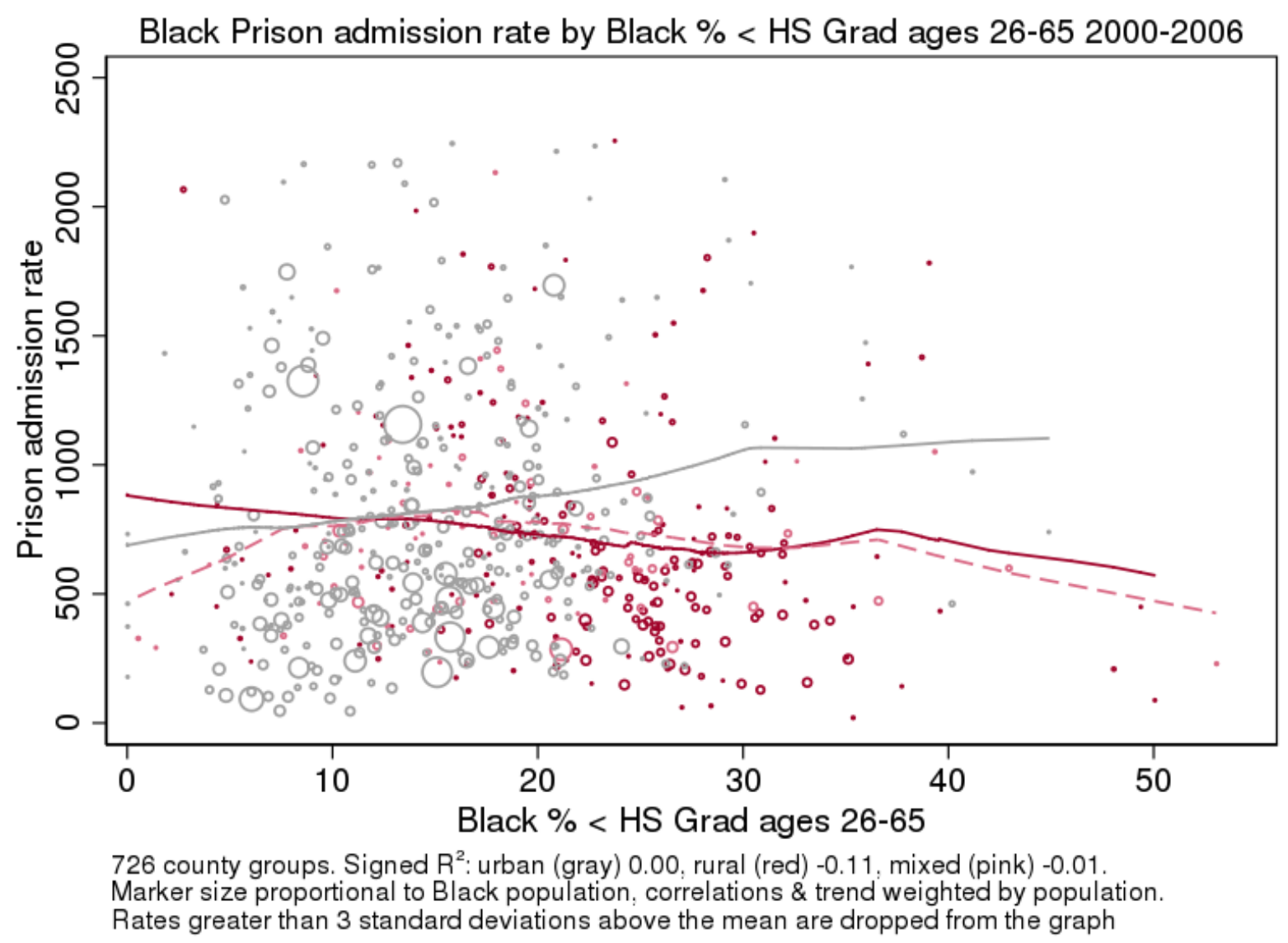




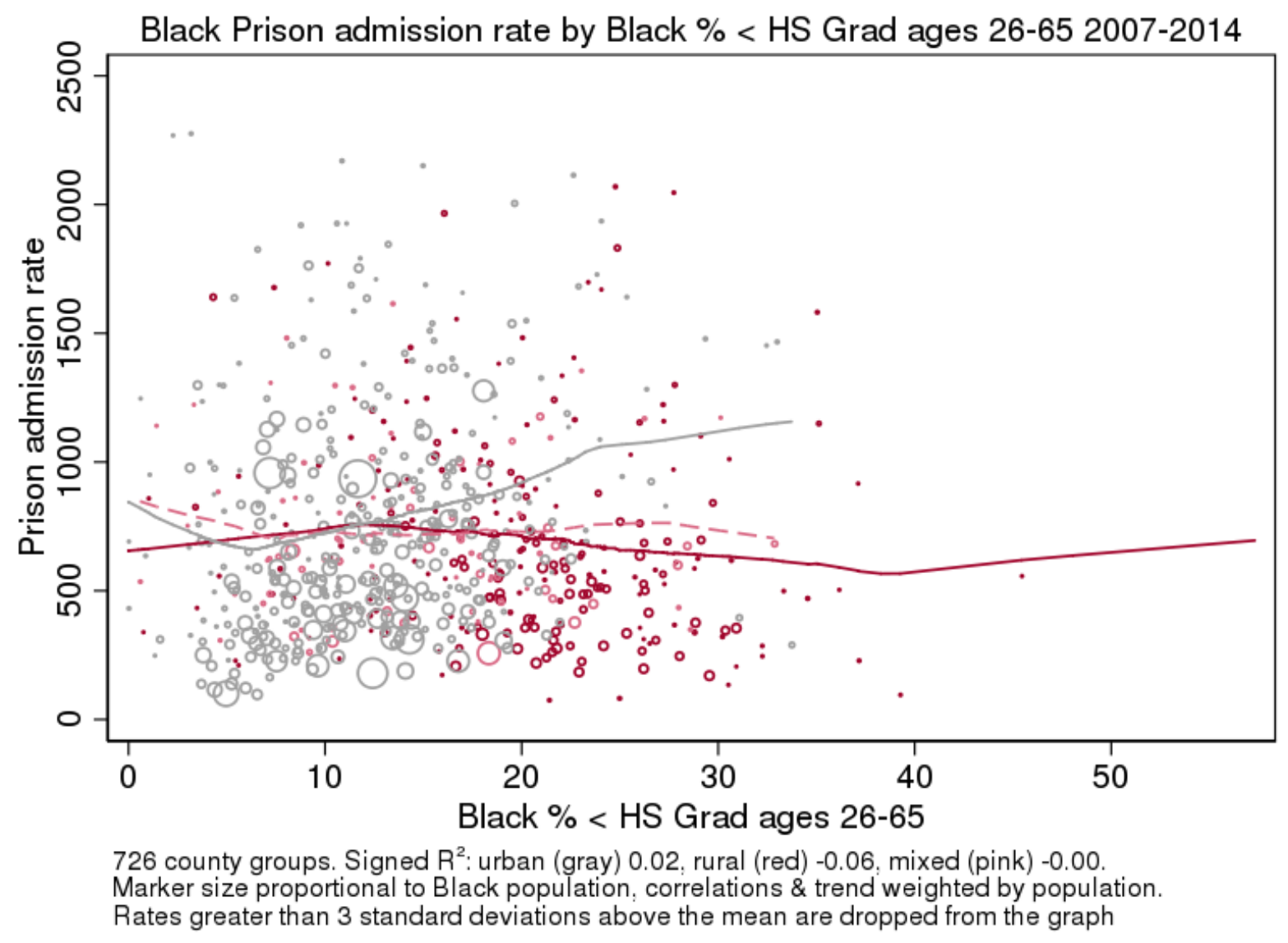




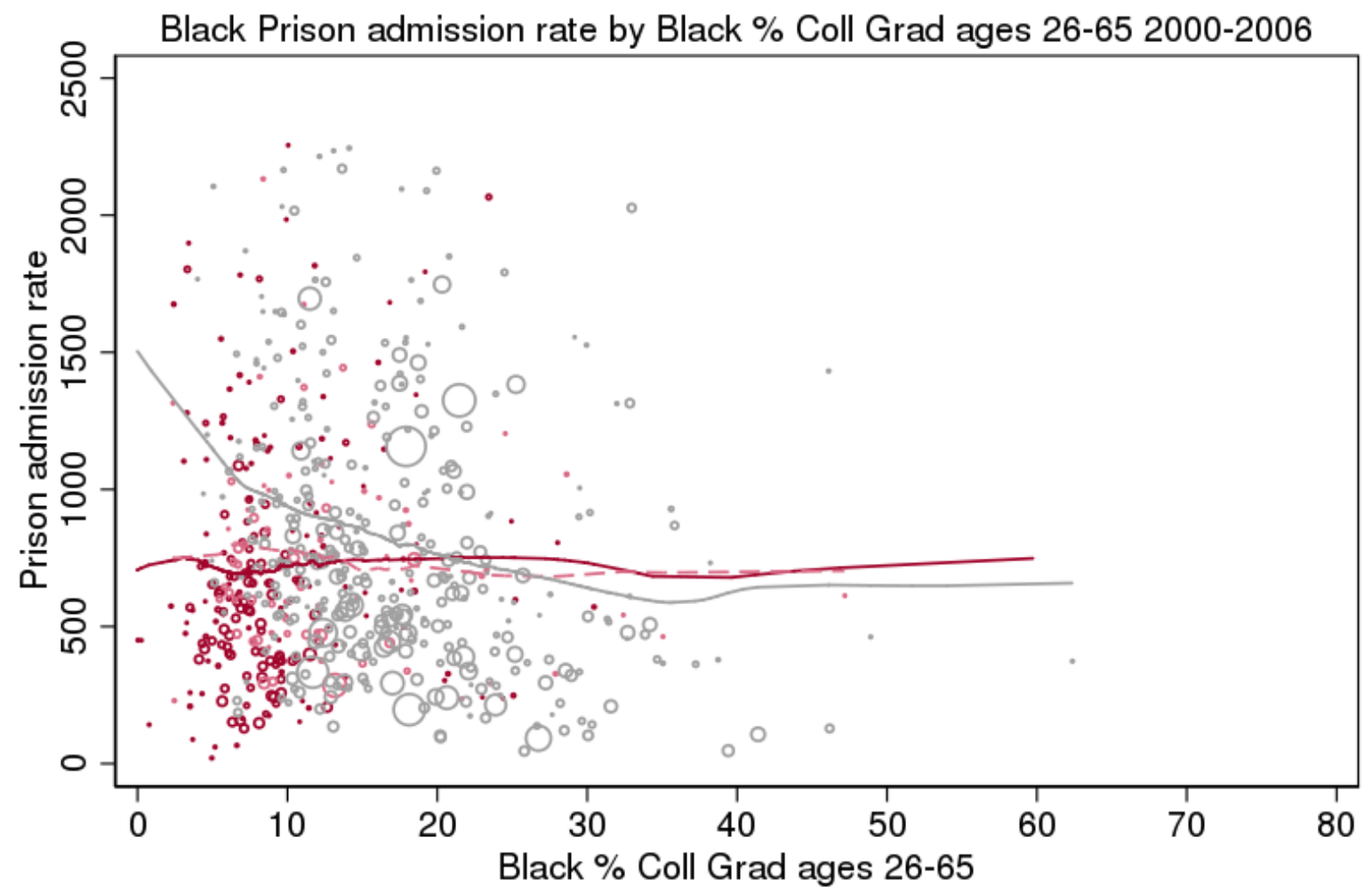

726 county groups. Signed $R^{2}$ : urban (gray) -0.03 , rural (red) 0.00 , mixed (pink) -0.00 . Marker size proportional to Black population, correlations \& trend weighted by population. Rates greater than 3 standard deviations above the mean are dropped from the graph 


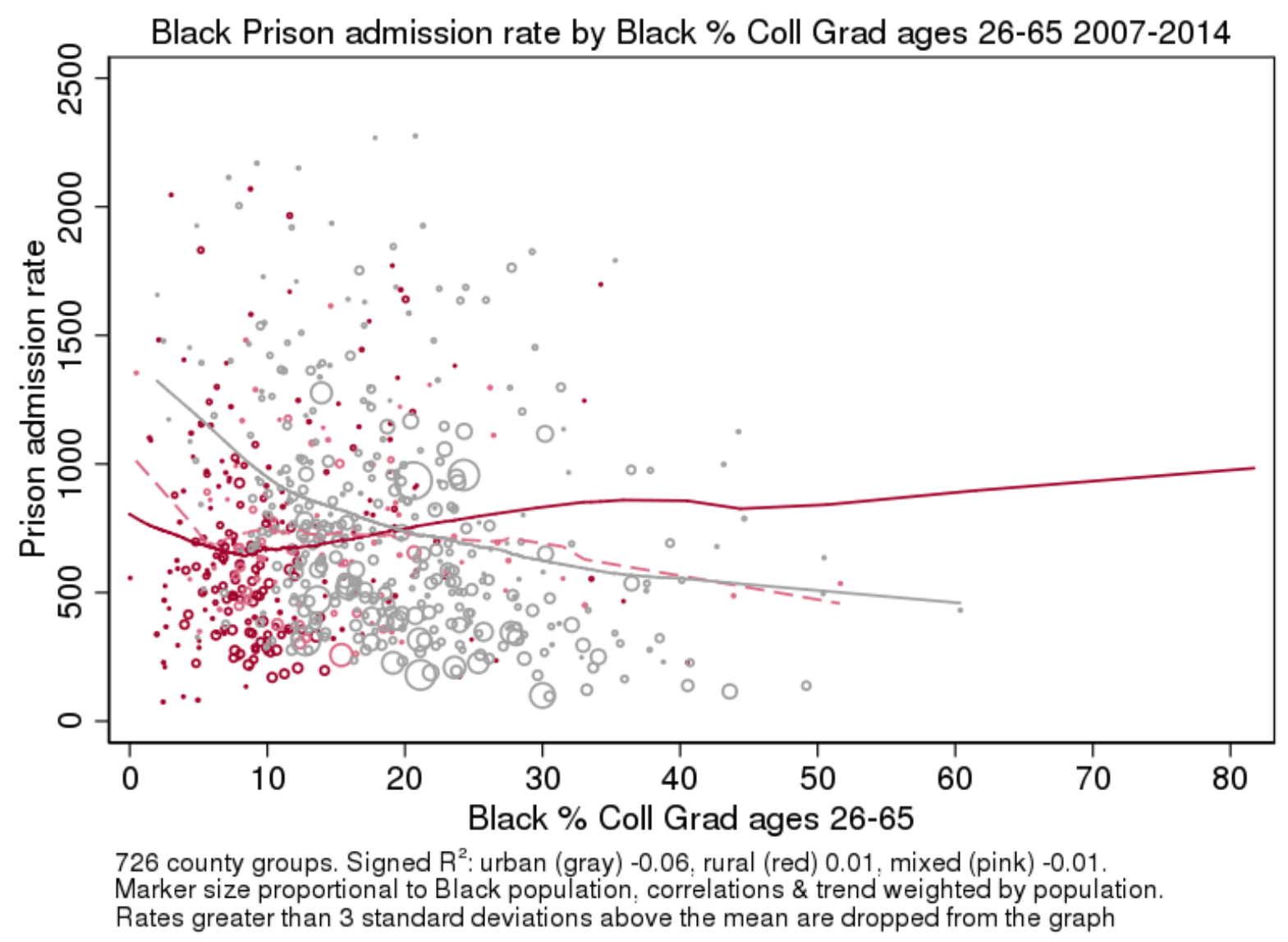




\section{Appendix C}

Scatterplots for change in the square root of the imprisonment rate by percent in poverty and percent college graduates. 
White change in sqrt prison admission rate 2000-2006 to 2007-2013 by lagged percent poor ages 26-65

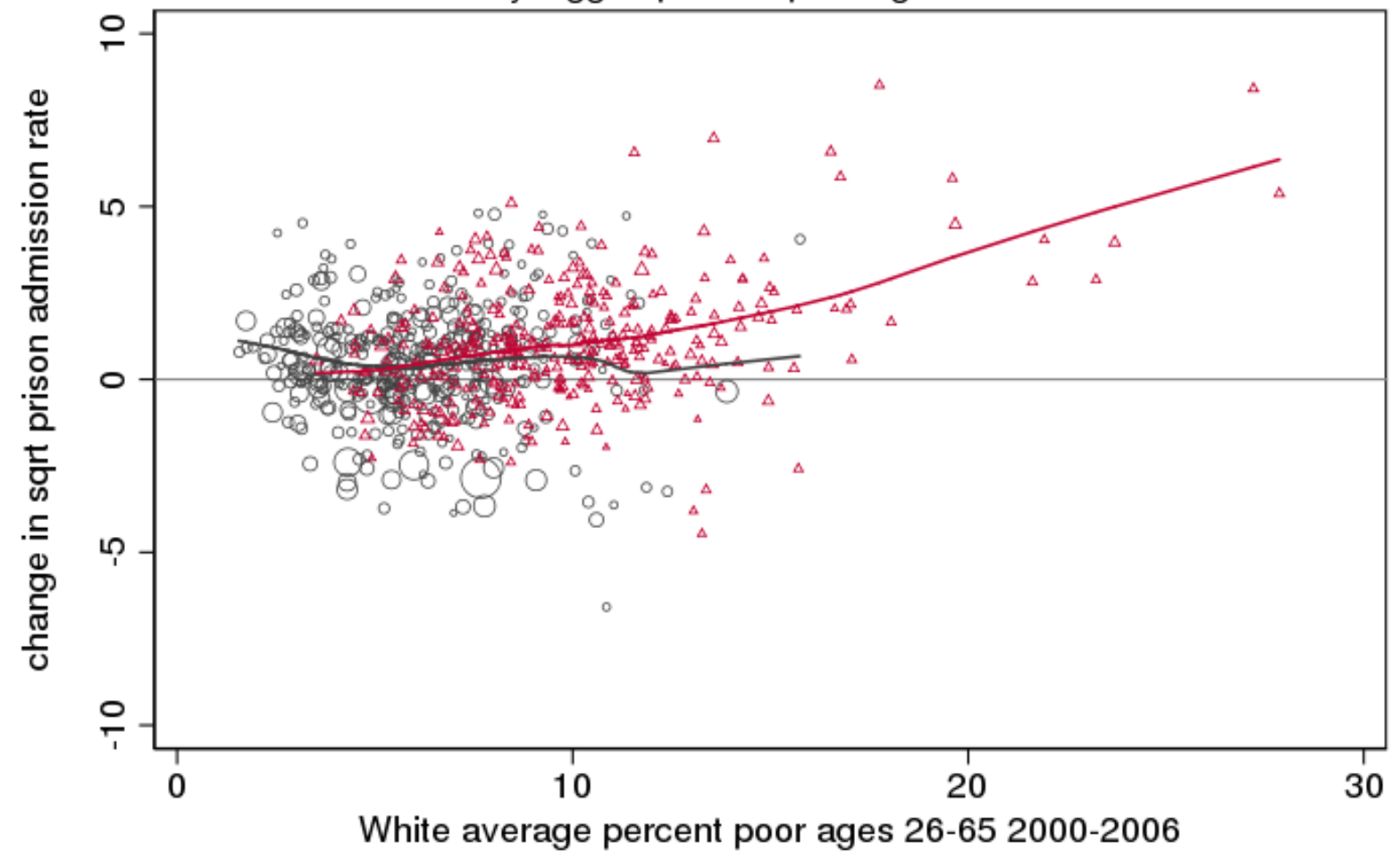

726 county groups. Marker size proportional to White population. Urban gray circles, signed $R^{2}=0$. Rural red triangles, signed $R^{2}=14$ 
White change in sqrt prison admission rate 2000-2006 to 2007-2013

by lagged percent college grads, ages 26-65

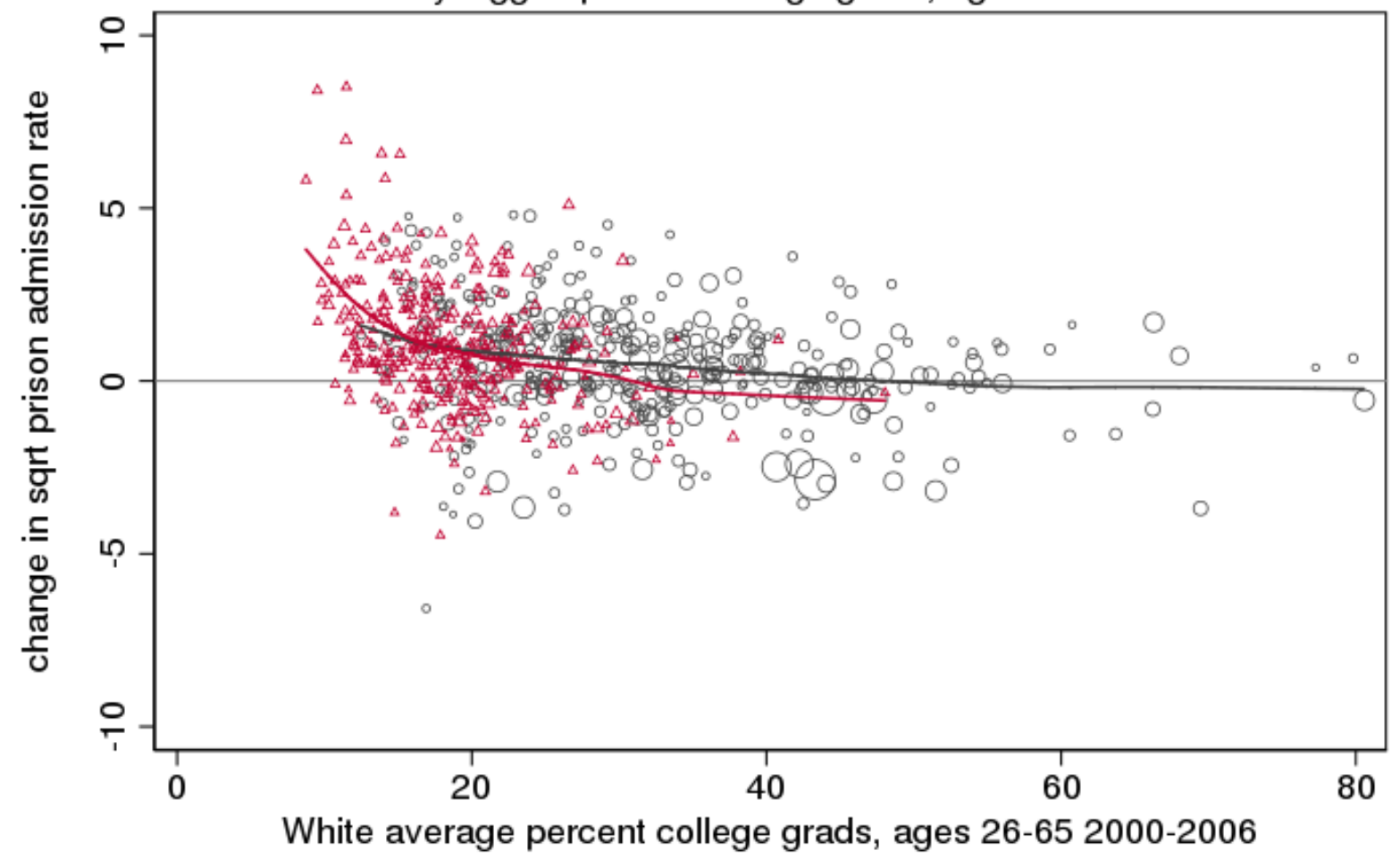

726 county groups. Marker size proportional to White population.

Urban gray circles, signed $R^{2}=04$. Rural red triangles, signed $R^{2}=.12$ 
Black change in sqrt prison admission rate 2000-2006 to 2007-2013 by lagged percent poor ages 26-65

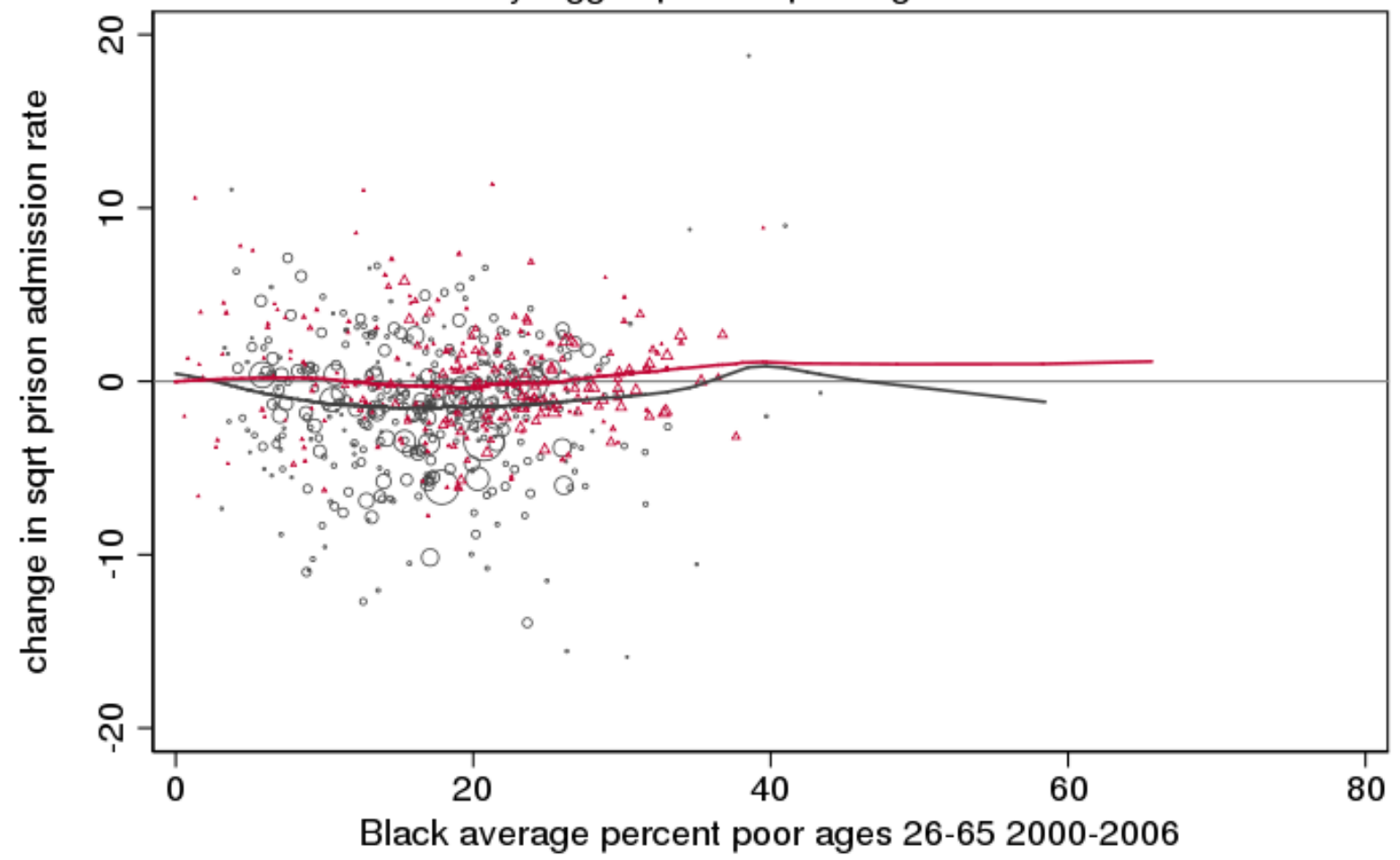

726 county groups. Marker size proportional to Black population. Urban gray circles, signed $R^{2}=0$. Rural red triangles, signed $R^{2}=0$ 
Black change in sqrt prison admission rate 2000-2006 to 2007-2013

by lagged percent college grads, ages 26-65

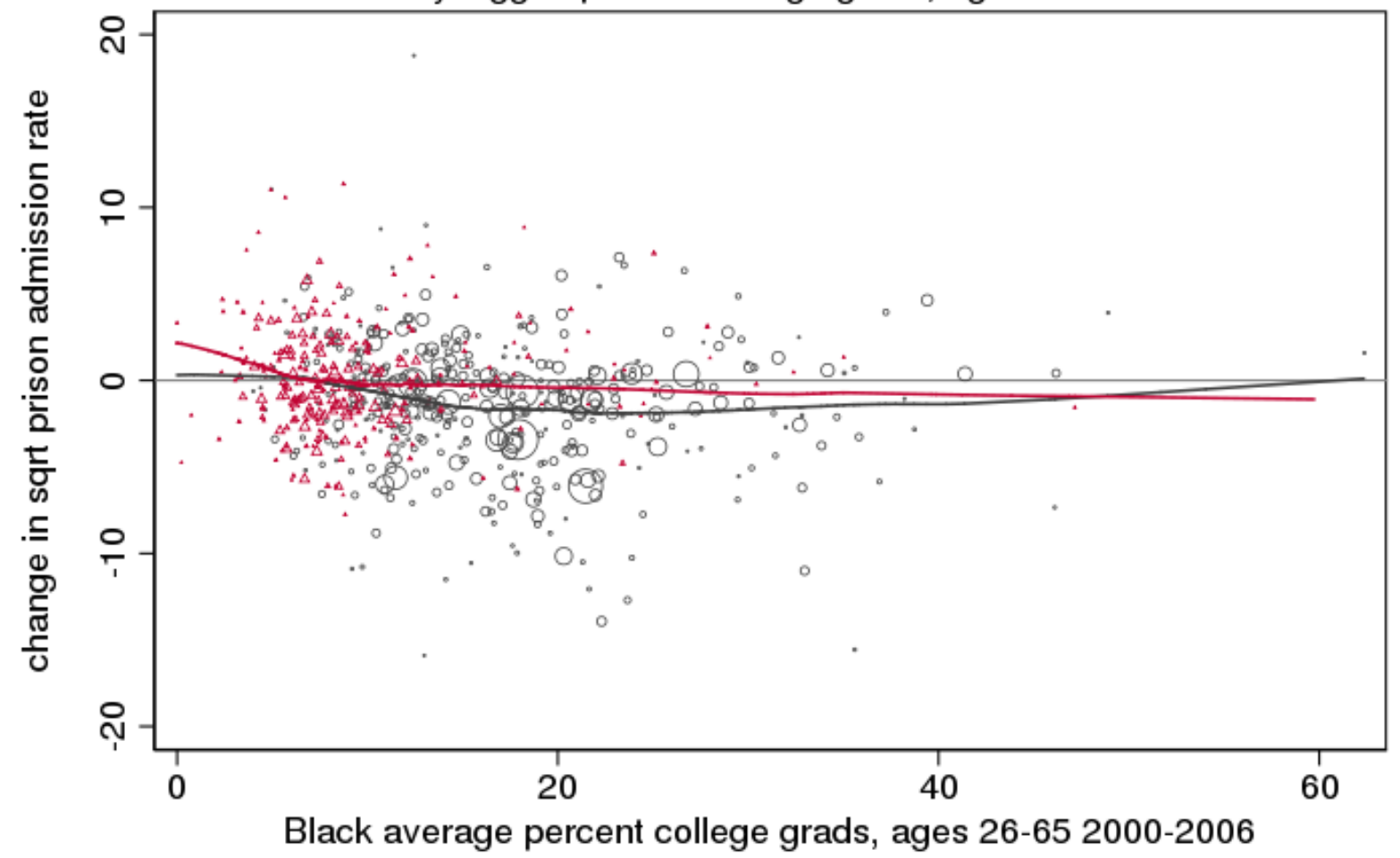

726 county groups. Marker size proportional to Black population.

Urban gray circles, signed $R^{2}=01$. Rural red triangles, signed $R^{2}=.01$ 